\title{
Credit Cycles with Market Based Household Leverage*
}

\author{
William Diamond \\ Wharton
}

\author{
Tim Landvoigt \\ Wharton \& NBER
}

December 2018

\begin{abstract}
We develop a model in which mortgage leverage available to households depends on the risk bearing capacity of financial intermediaries. Our model features a novel transmission mechanism from Wall Street to Main Street, as borrower households choose lower leverage and consumption when intermediaries are distressed. The model has financially constrained young and unconstrained middle-aged households in overlapping generations. Young households choose higher leverage and riskier mortgages than the middle-aged, and their consumption is particularly sensitive to credit supply. Relative to a standard model with exogenous credit constraints, the macroeconomic importance of intermediary net worth is magnified through its effects on household leverage, house prices, and consumption demand. The model quantitatively demonstrates how recessions with housing crises differ from those driven only by productivity, and how a growing demand for safe assets replicates many features of the 2000s credit boom and increases the severity of future financial crises.
\end{abstract}

*First draft: December 2018. Email addresses: diamondw@wharton.upenn.edu, timland@wharton.upenn.edu. We thank Carlos Garriga for useful feedback on our work. 


\section{Introduction}

Between 2000 and 2006, mortgage debt of US households relative to GDP rose by forty percentage points, with house prices rising in lockstep. This boom in the housing market was accompanied by an increase in the size of the financial sector, a compression of spreads on risky bonds, and a boom in debt-financed consumption. In the financial crisis of 2007-2009, a drop in house prices was accompanied by a sharp reduction in the size of the financial sector and the supply of credit, an increase in spreads on risky assets, the risk free rate falling to 0 , and a drop in consumption and output.

One common narrative of this episode, and of credit cycles more broadly, emphasizes the fact that rising house prices allowed homeowners to borrow in order to consume, and ascribes the recession to a fall in house prices and a reduction in consumption. Another argues that the boom and bust in the economy were driven primarily by the financial sector, with the recession being caused by a sharp drop in asset prices and credit supply due to the financial crisis. A third blames the roots of the boom-bust cycle largely on a scarcity of safe assets. The goal of this paper is to develop a quantitative framework that is rich enough to study these narratives jointly and analyze the connections between them.

Quantitative work on the 2000s credit cycle has made considerable progress by studying the effects of exogenous increases and decreases in credit constraints to model the boom and the bust. However, both the price and quantity of household leverage must respond to changes in credit supply and demand to connect the various narratives of the crisis. If households have a fixed loan to value ratio on their mortgages as is common in the literature, their leverage by construction cannot respond to changes in the supply of credit. If there is a relationship between the price of mortgage default risk and the amount of leverage households choose, it may be at the heart of how distress on Wall Street spills over to consumption on Main Street.

This paper develops a quantitative general equilibrium model in which household leverage is determined endogenously by market forces. The supply of credit is determined by the risk bearing capacity of financial intermediaries who are funded by deposits and equity that is costly to issue. Intermediaries offer households a menu of mortgage contracts from which to choose without any exogenous constraints on contract's terms. The households are in overlapping generations, with the consumption of the young distorted by their inability to borrow against growing non-pledgeable labor income. Because the young are the most borrowing constrained, they endogenously choose 
the highest leverage and riskiest mortgages, and their consumption is particularly sensitive to the supply of credit. We develop a tractable model of household heterogeneity in which agents in each generation aggregate to a representative agent ex-ante despite being heterogeneous ex post, using techniques similar to Constantinides and Duffie (1996). Intermediaries must ensure their deposits are riskless and meet regulatory capital requirements, so they charge particularly high rates on risky mortgages when they are short on equity capital. Our model of market based household leverage generalizes methods from a theoretical literature on endogenous leverage emphasizing belief disagreement (Geanakoplos (2010), Simsek (2013)) and adapted to financial intermediation by Diamond (2018), which has not appeared in quantitative work.

The model features an endowment of non-durables and housing, three generations of households which age in a perpetual-youth framework, and a bank which provides mortgages and issues deposits and equity. The young and middle aged are each endowed with a share of the economy's output, with a larger share going to the middle aged. Households are able to trade shares of their endowment within generations, but the only way to share risk between generations is through mortgage lending from the bank. The bank faces a cost of issuing equity required to bear risk in its mortgage portfolio. Mortgage leverage is determined endogenously by a borrower's preferences and the compensation the bank requires to bear default risk. Mortgage pricing depends on the borrower's income and wealth, mortgage leverage, and the bank's equity capital.

We use our model for three quantitative counterfactuals: comparing non-financial recessions driven by productivity with housing crises, understanding the equilibrium effects of a drop in the equity capital of intermediaries, and analyzing the effects of a growing demand for safe assets on the financial system and real economy. Housing recessions in our model are caused by shocks to the cross-sectional dispersion of house values, which we refer to as "housing risk shocks". High house price dispersion pushes more borrowers underwater and causes more mortgage defaults. In our first results, comparing the two types of recessions, we find several key differences. First, a productivity driven recession leads to an increase in the risk free rate, reflecting high growth expectations as the economy returns to trend. In a housing crisis, the losses of intermediaries' equity capital due to mortgage defaults impairs their ability to create safe assets. The resulting scarcity of safe assets leads to a drop in the risk free rate, consistent with the low rates during and after the 2008 financial crisis. Second, all households have similarly sized drops in consumption in the productivity driven recession, while in a housing crisis borrowing constrained young households face a disproportionate drop in consumption. This is because young consumers must borrow in order to consume, and intermediaries are less willing to bear 
the risk of lending to these risky borrowers after their loss of equity capital in the housing crisis. Third, the impaired ability of intermediaries to bear risk also leads to a large increase in mortgage spreads and to a drop in the leverage of all households in a household crisis, while the mortgage market is nearly unaffected by a productivity driven recession.

Next, we analyze the effects of a $30 \%$ drop in the equity capital of financial intermediaries on the economy. This loss impairs the ability of the intermediary to bear risk, leading to a shrinking of the intermediary's balance sheet and an increase in the spread charged on risky mortgages. This induces households to reduce their leverage. Because households cannot borrow as much against their houses, house prices experience a moderate drop that reflects their reduced value as a form of collateral. In addition, because households now have safer mortgages, default rates drop sharply. The intermediary gradually rebuilds its equity both through external issuance and retained earnings, which are high due to the low risk and high risk premium of mortgages. As intermediary capital converges back to its original level, other variables gradually revert as well.

Finally, we consider the general equilibrium effects of a growing demand for safe assets, considering both the effects during the credit and housing boom of the 2000s and the following bust and crisis. As discussed by Bernanke (2005), Caballero and Farhi (2018), and others, an increase in the demand for safe assets was a key macroeconomic feature of the economy before the financial crisis. Relative to existing literature, our model allows us to study the indirect effects of this growing demand on intermediary leverage and risk taking, household leverage, consumption, and house prices. Along a range of dimensions, we find that this increase in the demand for safe assets replicates features of the pre-crisis lending boom. In particular, we find that the size of the financial sector, the amount of mortage debt outstanding, the leverage of households, and the price of houses increase. If we further allow for a (perceived or actual) reduction in the likelihood of a housing risk shock, we can also generate a quantitatively small change in mortgage spreads despite a large rise in borrower leverage.

We then study how the economy with inflated house prices and mortgage debt, following the elevated demand for safe assets, responds to a housing risk shock, which causes more homeowners to default. Relative to an average economy drawn from the ergodic distribution, our high-safe-asset-demand economy is more vulnerable to this shock. The economy faces a sharp increase in mortgage defaults, which depletes the majority of the financial system's equity capital. This in turn induces banks to charge substantially higher spreads on mortgage debt for any given leverage, and as a result households cut back drastically on their mortgage leverage. Because our model connects household leverage 
choices with intermediary risk taking capacity, this counterfactual provides a rich illustration of how a growing demand for safe assets increases the size and riskiness of the financial sector and therefore the severity of financial crises.

Related Literature. A key feature of research in macroeconomics and finance since the 2008 financial crisis is a new understanding of how financial frictions impact the overall economy. A large and growing body of empirical research documents the macroeconomic roles of house prices, credit supply, and their impact on households' leverage and consumption. ${ }^{1}$ Another recent body of empirical work documents how distressed financial institutions reduce the supply of credit to households and firms, contributing to a drop in output and employment. ${ }^{2}$ Our goal is to develop a model that is consistent with and unifies findings in both empirical literatures as a framework for counterfactual analysis.

The quantitative macroeconomics literature after the housing boom has focused on models with exogenous housing collateral constraints following Iacoviello (2005), such as in Kiyotaki, Michaelides, and Nikolov (2011), Landvoigt, Piazzesi, and Schneider (2015), Favilukis, Ludvigson, and Van Nieuwerburgh (2017), and Guerrieri and Lorenzoni (2017). More recent work emphasized the importance of high household indebtedness and credit frictions for the severity of the bust, for example Guren, Krishnamurthy, and McQuade (2018) and Hedlund and Garriga (2018), or the relevance of household-level credit frictions for the transmission of monetary policy and other aggregate shocks, e.g. Elenev (2018), Wong (2018) and Greenwald (2018). Papers in this literature tighten or loosen exogenous collateral, leverage, or payment to income constraints to simulate a boom or bust. As pointed out by Justiniano, Primiceri, and Tambalotti (forthcoming), among others, it is necessary in such a framework to shock both households' borrowing constraints and constraints on the supply of mortgages to explain movements in both the prices and quantity of high leverage mortgages during the 2000-2006 housing boom. Our framework, in which a reduction in intermediaries' funding cost both lowers the price and raises the leverage of household debt, provides a single explanation for these facts.

Corbae and Quintin (2015) is the only paper we know in this literature where households choose the leverage of their mortgage. They study a framework where households face a menu of mortgage contracts offered by a risk-neutral lender subject to exogenous

\footnotetext{
${ }^{1}$ for example Mian and Sufi (2011), Mian, Rao, and Sufi (2013), Favara and Imbs (2015), Di Maggio, Kermani, Keys, Piskorski, Ramcharan, Seru, and Yao (2017), Di Maggio and Kermani (2017), Adelino, Schoar, and Severino (2016), and Foote, Lowenstein, and Willen (2016)

2 for example Chodorow-Reich (2014), Chodorow-Reich and Falato (2018), Benmelech, Meisenzahl, and Ramcharan (2014), and Ramcharan, Verani, and Van Den Heuvel (2016)
} 
constraints and select endogenously into high and low leverage mortgages. To our knowledge, ours is the first quantitative paper to model heterogeneous borrowers facing a menu of leverage choices priced by constrained intermediaries in general equilibrium.

A separate research agenda in finance on intermediary asset pricing (He and Krishnamurthy (2013), Adrian, Etula, and Muir (2014), He, Kelly, and Manela (2017)) has shown empirically and quantitatively that the risk taking capacity of financial intermediaries is a key driver of asset prices. This approach to asset pricing successfully explains prices in a range of asset classes and is particularly important for pricing highly intermediated assets such as derivatives, bonds, and commodities (Haddad and Muir (2018)). Of particular relevance to our model is the empirical evidence (Gabaix, Krishnamurthy, and Vigeron (2007), Hanson (2014)) that the pricing of mortgage risk is sensitive to the risk taking capacity of specialized intermediaries. Relative to this literature, our contribution is to connect the pricing kernel of a constrained financial intermediary to the leverage choices of the agents that borrow from it.

Finally, our paper provides a potential resolution to the question whether the boombust episode was caused by loose credit constraints, or high expected future house prices (Kaplan, Mitman, and Violante (2017)). In our framework, a large positive shock to the demand for safe assets leads to a relaxation of credit constraints, and simultaneously puts the economy on a path of rising house prices. This integrates the three narratives about the origins of the financial crisis mentioned above, in a manner that depends crucially on the role of financial intermediaries in our model as both mortgage lenders and creators of safe assets. While existing work connects the demand for safe assets to financial fragility (Caballero and Krishnamurthy (2009)), the indirect effects of a safe asset shortage on househould leverage and consumption is new to our paper.

\section{Model}

\subsection{Income and housing endowment}

Aggregate output is $Y_{t}=\bar{Y}_{t} \tilde{Y}_{t}$, where $\bar{Y}_{t}$ is the income trend and grows at the deterministic rate $g$, i.e. $\bar{Y}_{t}=\bar{Y}_{t-1} \exp (g) . \tilde{Y}_{t}$ is the cyclical component and follows an $\mathrm{AR}(1)$ in logs

$$
\log \left(\tilde{Y}_{t}\right)=\left(1-\rho_{y}\right) \mu_{y}+\rho_{y} \log \left(\tilde{Y}_{t-1}\right)+\varepsilon_{t}
$$

where $\varepsilon_{t}$ is i.i.d. and normally distributed with mean zero. 
The economy is endowed with a constant stock of housing capital $\bar{H}$. Housing capital produces housing services according to the linear technology

$$
s_{t}=n\left(h_{t}, \bar{Y}_{t}\right)=h_{t} \bar{Y}_{t}
$$

and owners of housing capital need to spend fraction $\delta_{H}$ of the capital value on maintenance each period.

\subsection{Demographics and Preferences}

The economy is populated a continuum of households in three generations: old, middle aged, and young. Young and middle aged households respectively have probabilities $\pi^{Y}$ and $\pi^{M}$ of becoming middled aged and becoming old, drawn i.i.d across households. Old households live for one period. Each period, a measure one of new young households are born and the same measure of old households die. The population of each generation is constant, with measure $\frac{1}{\pi^{Y}}$ young, $\frac{1}{\pi^{M}}$ middle aged, and 1 old households.

All households maximize expected utility with discount factor $\beta$ and constant relative risk aversion $\gamma$. Young and middle aged consume a non-durable numeraire consumption good and housing services. Intraperiod preferences over both goods are represented by a Cobb-Douglas aggregator with weight $\theta$ on housing services. They further derive utility from liquidity services provided by bank deposits. Old households derive utility only from non-durable consumption and bequests paid to younger households. In addition, middle aged household discount their utility when old by an additional factor $\beta^{O}$. Househoulds maximize the expected value of a discounted sum of their period utility across each period of their life.

\subsection{Markets}

Households have acess to competitive markets for housing, mortgages, bank deposits, and bank equity. In addition, households within each generation are able to trade shares of their endowment of labor income but not with agents from other generations. This endowment pays in aggregate $Y_{t}^{*}$, equal to $Y_{t}$ plus an additional term that reflects rebates of bankruptcy costs to households, to be defined below in equation (14). ${ }^{3}$ Agents are also

\footnotetext{
${ }^{3}$ Mortgage default creates losses for banks, part of which are true deadweight costs to society, and part of which due to fire sales or factor payments to actors involved in the foreclosure process. The latter part of mortgage losses is rebated to households in proportion to endowment income.
} 
able to frictionlessly rent housing from other members of their own generation (though in equilibrium this rental market will not be used and can be viewed as a tool for analytical tractability). Because the rental markets for housing are segmented by generation, the equilibrium rental rate for housing is different for agents of different generations. Bank equity is available only to middle aged agents, while all agents face the same risk free interest rate on bank deposits.

In addition, agents of each generation face a menu of mortgage contracts offered by a financial intermediary from which they can choose. Mortgages can only be held by the financial intermediary, so households cannot buy them directly. These mortgages are priced by the intermediary's stochastic discount factor, which is influenced both by the preferences of middle aged households who own its equity as well as the severity of financial frictions that distort its behavior.

\subsection{Problem of old generation}

Households of the old generation have beginning-of-period wealth $w_{t}^{O}$, given by the payoff of the asset portfolio they purchased when middle-aged. They divide their wealth into consumption $c_{t}^{O}$ and bequests $B_{t}^{O}$ in order to maximize their utility function

$$
\frac{1}{1-\gamma}\left(\left(c_{t}^{O}\right)^{1-\gamma}+\phi\left(B_{t}^{O}\right)^{1-\gamma}\right)
$$

They optimally choose to consume $c_{t}^{O}=\frac{1}{1+\phi^{\frac{1}{\gamma}}} w_{t}^{O}$ and bequeath $B_{t}^{O}=\frac{\phi^{\frac{1}{\gamma}}}{1+\phi^{\frac{1}{\gamma}}} w_{t}^{O}$ yielding a total amount of utility

$$
u^{O}\left(w_{t}^{O}\right)=\frac{\left(w_{t}^{O}\right)^{1-\gamma}}{1-\gamma}\left[\left(\frac{1}{1+\phi^{\frac{1}{\gamma}}}\right)^{1-\gamma}+\phi\left(\frac{\phi^{\frac{1}{\gamma}}}{1+\phi^{\frac{1}{\gamma}}}\right)^{1-\gamma}\right] .
$$

\subsection{Problem of middle generation}

The middle aged obtain utility from consuming non-durables and housing as well as from their holding of bank deposits. They begin the period with wealth $w_{t}^{M}$ which they can spend by consuming non-durables, renting housing, buying housing, investing in bank deposits, or investing in bank equity. In addition they can take out a mortgage from the bank collateralized by their house and can choose the loan-to-value ratio of the mortgage, taking as given the menu of contracts offered by the bank. Their period utility function 
depends on nondurable consumption $c_{t}^{M}$, housing consumption $s_{t}^{M}$ and deposit holdings $d_{t}^{M}$ as follows:

$$
u^{M}\left(c_{t}^{M}, s_{t}^{M}, d_{t}^{M}\right)=\frac{1}{1-\gamma}\left(\left(c_{t}^{M}\right)^{1-\theta}\left(s_{t}^{M}\right)^{\theta}\right)^{1-\gamma}+\psi^{M} \frac{\left(d_{t}^{M}\right)^{1-\gamma}}{1-\gamma} .
$$

After the middle aged choose their consumption and investments, they face a probability $\pi^{M}$ of becoming old (or otherwise remain middle aged) and also face an idiosyncratic shock to the value of their housing. If they finished period $t$ owning $h$ units of housing, they have at period $\mathrm{t}+1 \epsilon_{t+1}^{M} h$ units of housing, where $\epsilon_{t+1}^{M}$ is a mean one lognormal random variable, drawn i.i.d. across households and across time. The variance of $\epsilon_{t+1}^{M}$ evolves as a binary Markov chain. They choose whether to default on their mortgage after these shocks are realized. If they default, a fraction $\lambda^{M}$ of their wealth is lost. ${ }^{4}$ Each household chooses whether or not to default in order to maximize their continuation utility.

Denote the post-default-decision wealth of a middle-aged household by $w_{t}^{M}$. This is the only individual state variable. Denote all other state variables exogenous to the household by $\mathcal{Z}_{t}$. Denote the vector of portfolio choices of the middle-aged by $\alpha_{t}^{M}=$ $\left[h_{t}^{M}, b_{t}^{M}, d_{t}^{M}, m_{t}^{M}\right]$, where the elements of this vector are respectively the choice of housing, bank equity, deposits, and the face value of the mortgage. Let $q^{M}\left(\alpha_{t}^{M}\right) m_{t}^{M}$ be the amount the intermediary is willing to lend if the household chooses a portfolio $\alpha_{t}^{M}$ and mortgage face value of $m_{t}^{M} \cdot q^{M}\left(\alpha_{t}^{M}\right)$ is assumed to be homogenous of degree 0 in its arguments, which will be derived below from the intermediary's optimization problem.

The full problem of a middle-aged household is

$$
\begin{aligned}
V^{M}\left(w_{t}^{M}, \mathcal{Z}_{t}\right)= & \max _{c_{t}^{M}, s_{t}^{M}, \alpha_{t}^{M}} u^{M}\left(c_{t}^{M}, s_{t}^{M}, d_{t}^{M}\right) \\
& +\beta\left(1-\pi^{M}\right) \mathrm{E}_{t}\left[\max \left\{V^{M}\left(w_{t+1}^{M, d}, \mathcal{Z}_{t+1}\right), V^{M}\left(w_{t+1}^{M, n d}, \mathcal{Z}_{t+1}\right)\right\}\right] \\
& +\beta \beta^{O} \pi^{M} \mathrm{E}_{t}\left[\max \left\{u^{O}\left(w_{t+1}^{M, d}\right), u^{O}\left(w_{t+1}^{M, d}\right)\right\}\right],
\end{aligned}
$$

subject to the budget constraint

$$
w_{t}^{M}=c_{t}^{M}+\rho_{t}^{M} s_{t}^{M}+h_{t}^{M} P_{t}-\rho_{t}^{M} n\left(h_{t}^{M}, \bar{Y}_{t}\right)+p_{t}^{I} b_{t}^{M}+\frac{d_{t}^{M}}{1+r_{t}}-q^{M}\left(\alpha_{t}^{M}\right) m_{t}^{M},
$$

\footnotetext{
${ }^{4}$ This lost wealth is not destroyed but is added lump-sum to the endowment income $Y_{t}^{*}$.
} 
and the definition of next-period wealth for non-defaulters

$$
w_{t+1}^{M, n d}=\left(1-\delta_{H}\right) P_{t+1} \epsilon_{t+1}^{M} h_{t}^{M}+d_{t}^{M}+b_{t}^{M}\left(p_{t+1}^{I}+x_{t+1}\right)-m_{t}^{M} .
$$

and for defaulters

$$
w_{t+1}^{M, d}=\left(1-\lambda^{M}\right)\left(d_{t}^{M}+b_{t}^{M}\left(p_{t+1}^{I}+x_{t+1}\right)\right),
$$

where $x_{t}^{I}$ is the dividend per share paid by intermediaries to be defined below. Note that middle-aged household discount the utility of becoming old by the additional factor $\beta^{O}<1$. This additional discounting reflects that we view the utility of the old as being spread over many future periods (retirement), even though we model their lifespan as one period.

\subsubsection{Characterization of the Middle Generation Problem}

The following proposition provides the key result for characterizing the optimization problem in (2).

Proposition 1. 1. The value function of the middle-aged has the form

$$
V^{M}\left(w_{t}^{M}, \mathcal{Z}_{t}\right)=v^{M}\left(\mathcal{Z}_{t}\right) \frac{\left(w_{t}^{M}\right)^{1-\gamma}}{1-\gamma}
$$

where $v^{M}\left(\mathcal{Z}_{t}\right)$ only depends on aggregate state variables.

2. The choice vector $\left[c_{t}^{M}, s_{t}^{M}, h_{t}^{M}, b_{t}^{M}, d_{t}^{M}, m_{t}^{M}\right]$ is linear in individual wealth $w_{t}^{M}$, conditional on the aggregate state. As a result, the decisions made at time t by the middle aged generation are independent of the time $t$ wealth distribution within the generation.

3. Because the amount of housing owned and consumed by middle aged agents is linear in wealth, the housing market only clears if every agent consumes precisely as much housing as it owns. As a result, the allocation is the same as if the rental market did not operate.

Proof. See appendix.

Proposition 1 has two key implications. First, although middle-aged agents behave like a representative agent in their consumption and portfolio choice ex ante, they are not insured ex post against the idiosyncratic shocks to the value of the houses they own. As a result, only households who face a sufficiently bad idiosyncratic housing shock will choose to default. The key to this combination of aggregating to a representative agent ex 
ante (necessary for numerical tractability) and heterogeneity ex post (necessary to meaningfully calibrate the model) is that agents face shocks which are multiplicative in the amount of housing they own. As explained in Constantinides and Duffie (1996), this sort of multiplicative shock cannot be avoided by trading financial assets within the generation when agents have CRRA utility, so choices naturally aggregate as if each middle aged household was a representative agent in autarky.

Second, the mortgages given to all middle aged households are equally risky. Richer middle aged households borrow more and buy more housing than poorer ones, but the endogenously optimal degree of leverage is the same for all middle aged households. This result (which is key for proving the aggregation proposition above) comes from the fact that the mortgage pricing function $q^{M}$ is homogeneous of degree zero. That is, an agent with twice as much housing, twice as much mortgage face value, and twice the financial portfolio of another will be provided with twice as much of a loan by the intermediary. The property of the mortgage pricing function is derived from the optimal behavior of the financial intermediary below. Middle aged households default if and only if their wealth (inclusive of the costs of default) will be higher than if they did not default. That is, they default for any realization of $\epsilon_{t+1}^{M}$ such that

$$
\begin{gathered}
\left(1-\lambda^{M}\right)\left(d_{t}^{M}+b_{t}^{M}\left(p_{t+1}^{I}+x_{t+1}\right)\right)>\left(1-\delta_{H}\right) P_{t+1} \epsilon_{t+1}^{M} h_{t}^{M}+d_{t}^{M}+b_{t}^{M}\left(p_{t+1}^{I}+x_{t+1}\right)-m_{t}^{M}, \\
\left(m_{t}^{M}-\lambda^{M}\left(d_{t}^{M}+b_{t}^{M}\left(p_{t+1}^{I}+x_{t+1}\right)\right)\right) \frac{1}{\left(1-\delta_{H}\right) P_{t+1} h_{t}^{M}}>\epsilon_{t+1}^{M},
\end{gathered}
$$

This relation defines a cutoff value $\bar{\epsilon}_{t+1}^{M}$ such that the middle aged default if and only if their realized $\epsilon_{t+1}^{M}$ is lower. The fact that this cutoff is the same for all middle aged agents, regardless of how much wealth they have, is crucial for the model to aggregate tractably.

Corollary 1. There exists a default threshold $\bar{\epsilon}_{t+1}^{M}$ such that middle-aged with $\epsilon_{t+1}^{M}<\bar{\epsilon}_{t+1}^{M}$ default. The aggregate default rate of the middle generation is $F_{\epsilon, t}^{M}\left(\bar{\epsilon}_{t+1}^{M}\right)$.

\subsection{Problem of young generation}

Young households are similar to middle aged households, except that they will be paid endowment income in the future, which cannot be pledged to agents outside of their generation. As a result, young households are effectively liquidity constrained. To allow for tractable aggregation while preserving this liquidity constraint, we allow young households to trade shares of their endowment income with other young agents. However, all endowment shares must be owned by some young household. If the young were able 
to pledge their endowment income to other generations, they would sell some of it to consume.

Young households receive a fraction $v$ of the aggregate endowment at the beginning of the period. The remaining fraction $1-v$ is paid out to the newly middle-aged (those middle aged who were young in the previous period). Young households trade shares of an asset in unit supply that entitles to proportional payouts of the endowment $v Y_{t}^{*}$ while young, and $(1-v) Y_{t}^{*}$ when turning middle-aged. The shares expire upon turning middle-aged. Newborn young are endowed with fraction $\pi^{Y}$ of the asset. Denote the "share price" of the asset by $p_{t}^{Y}$. Note that this price is special in that it trades on a market only availale to young households. That said, the problem of the young is most tractably described by computing their wealth including this "market value" of their endowment (in a special market accessible only to the young), since this yields a single state variable that determines their behavior. The wealth of newborn agents is

$$
w_{t}^{Y, 0}=\pi^{Y}\left(\nu Y_{t}^{*}+p_{t}^{Y}\right)
$$

Like the middle aged, the young can also invest in deposits, buy and rent housing, and take out a mortgage. Their period utility function is

$$
u^{Y}\left(c_{t}^{Y}, s_{t}^{Y}, d_{t}^{Y}\right)=\frac{1}{1-\gamma}\left(\left(c_{t}^{Y}\right)^{1-\theta}\left(s_{t}^{Y}\right)^{\theta}\right)^{1-\gamma}+\psi^{Y} \frac{\left(d_{t}^{Y}\right)^{1-\gamma}}{1-\gamma} .
$$

Because the young may not be as safe of borrowers as the middle aged, the intermediary provides them a different amount of credit for a given portfolio and mortgage face value. Write the vector of portfolio choices of the young as $\alpha_{t}^{Y}=\left[h_{t}^{Y}, m_{t}^{Y}, d_{t}^{Y}, \eta_{t}^{Y}\right]$.

We can now write the problem of a household in the young generation as

$$
\begin{aligned}
V^{Y}\left(w_{t}^{Y}, \mathcal{Z}_{t}\right)= & \max _{c_{t}^{Y}, s_{t}^{Y}, \alpha_{t}^{Y}} u^{Y}\left(c_{t}^{Y}, s_{t}^{Y}, d_{t}^{Y}\right) \\
& +\beta\left(1-\pi^{Y}\right) \mathrm{E}_{t}\left[\max \left\{V^{Y}\left(w_{t+1}^{Y Y, d}, \mathcal{Z}_{t+1}\right), V^{Y}\left(w_{t+1}^{Y Y, n d}, \mathcal{Z}_{t+1}\right)\right\}\right] \\
& +\beta \pi^{Y} \mathrm{E}_{t}\left[\max \left\{V^{M}\left(w_{t+1}^{Y M, d}, \mathcal{Z}_{t+1}\right), V^{M}\left(w_{t+1}^{Y M, n d}, \mathcal{Z}_{t+1}\right)\right\}\right]
\end{aligned}
$$

subject to

$$
w_{t}^{Y}=c_{t}^{Y}+\rho_{t}^{Y} s_{t}^{Y}+P_{t} h_{t}^{Y}+p_{t}^{Y} \eta_{t}^{Y}-\rho_{t}^{Y} n\left(h_{t}^{Y}, \bar{Y}_{t}\right)-q^{Y}\left(\alpha_{t}^{Y}\right) m_{t}^{Y}+\frac{d_{t}^{Y}}{1+r_{t}} .
$$


Next-period wealth while remaining young is, for defaulters and non-defaulters, respectively,

$$
w_{t+1}^{Y Y, d}=\left(1-\lambda^{Y}\right)\left(d_{t}^{Y}+\eta_{t}^{Y}\left(\nu Y_{t+1}^{*}+p_{t+1}^{Y}\right)\right)
$$

and

$$
w_{t+1}^{Y Y, n d}=\left(1-\delta_{H}\right) P_{t+1} \epsilon_{t+1}^{Y} h_{t}^{Y}-m_{t}^{Y}+d_{t}^{Y}+\eta_{t}^{Y}\left(v Y_{t+1}^{*}+p_{t+1}^{Y}\right),
$$

respectively. $\epsilon_{t+1}^{\gamma}$ is an idiosyncratic multiplicative shock to the value of a young household's housing that is i.i.d. across households and time. The variance of $\epsilon_{t+1}^{Y}$ changes over time and is driven by the same binary Markov chain as $\epsilon_{t+1}^{M}$. Note that like the middle aged, the young lose a fraction $\lambda^{Y}$ of their wealth when they default, and these losses are similarly paid out in proportion to the holders of shares of the economy's endowment rather than destroyed. For young that turn middle-aged, these expressions are

$$
w_{t+1}^{Y M, d}=\left(1-\lambda^{Y}\right)\left(d_{t}^{Y}+\eta_{t}^{Y}\left((1-v) Y_{t+1}^{*}+B_{t+1}^{O}\right)\right),
$$

and

$$
w_{t+1}^{Y M, n d}=\left(1-\delta_{H}\right) P_{t+1} \epsilon_{t+1}^{M} h_{t}^{Y}-m_{t}^{Y}+d_{t}^{Y}+\eta_{t}^{Y}\left((1-v) Y_{t+1}^{*}+B_{t+1}^{O}\right) .
$$

Young that turn middle-aged get bequests from old households, $B_{t+1}^{O}$. To maintain aggregation, we assume that this bequest is paid in proportion to the ownership of the endowment shares $\eta_{t}^{Y}$. Note that the young generation is exposed to both aggregate shocks (which will affect the prices of assets it owns) as well as to an idiosyncratic shock to the value of the housing it owns. This idiosyncratic shock cannot be insured against, and those young households with the worst shocks to their housing will chose to default on their mortgages.

\subsubsection{Characterization of the Young Generation Problem}

Since young households can trade shares to their endowment income with each other, we can show that the savings and consumption choices of the young are equivalent to one of a representative young household ex ante, even though they do not perfectly share risk ex post.

Proposition 2. 1. The value function of the young has the form

$$
V^{Y}\left(w_{t}^{Y}, \mathcal{Z}_{t}\right)=v^{Y}\left(\mathcal{Z}_{t}\right) \frac{\left(w_{t}^{Y}\right)^{1-\gamma}}{1-\gamma}
$$

where $v^{Y}\left(\mathcal{Z}_{t}\right)$ only depends on aggregate state variables. 
2. The choice vector $\left[c_{t}^{Y}, s_{t}^{Y}, h_{t}^{Y}, d_{t}^{Y}, m_{t}^{Y}, \eta_{t}^{Y}\right]$ is linear in individual wealth $w_{t}^{Y}$, conditional on the aggregate state. As a result, the decisions made at time t by the young generation are independent of the time $t$ wealth distribution within the generation.

3. Because the amount of housing owned and consumed by young agents is linear in wealth, the housing market only clears if every agent consumes precisely as much housing as it owns. As a result, the allocation is the same as if the rental market did not operate.

Proof. See appendix.

Proposition 2 has direct implications for the optimal default decisions of young households, which is analogous to proposition 1 for middle-aged. The young choose to default if and only if their wealth is higher than if they did not default. This occurs if

$$
\left(1-\lambda^{Y}\right)\left(d_{t}^{Y}+\eta_{t}^{Y}\left(v Y_{t+1}^{*}+p_{t+1}^{Y}\right)\right)>\left(1-\delta_{H}\right) P_{t+1} \epsilon_{t+1}^{Y} h_{t}^{Y}-m_{t}^{Y}+d_{t}^{Y}+\eta_{t}^{Y}\left(v Y_{t+1}^{*}+p_{t+1}^{Y}\right)
$$

and

$\left(1-\lambda^{Y}\right)\left(d_{t}^{Y}+\eta_{t}^{Y}(1-v) Y_{t+1}^{*}\right)>\left(1-\delta_{H}\right) P_{t+1} \epsilon_{t+1}^{M} h_{t}^{Y}-m_{t}^{Y}+d_{t}^{Y}+\eta_{t}^{Y}\left((1-v) Y_{t+1}^{*}+B_{t+1}^{O}\right)$

respectively if the household stays young or becomes middle aged. These inequalities each hold if $\epsilon_{t+1}^{Y}$ and $\epsilon_{t+1}^{M}$ are sufficiently low, proving the following proposition.

Proposition 3. There exist default thresholds $\left(\bar{\epsilon}_{t+1}^{Y, Y}, \bar{\epsilon}_{t+1}^{Y, M}\right)$ such that young transitioning to young with $\epsilon_{t+1}^{Y}<\bar{\epsilon}_{t+1}^{Y, Y}$, and young transitioning to middle-aged with $\epsilon_{t+1}^{M}<\bar{\epsilon}_{t+1}^{Y, M}$, default. The aggregate default rate at time $t+1$ of the young at time $t$ is

$$
\left(1-\pi^{Y}\right) F_{\epsilon, t}^{Y}\left(\bar{\epsilon}_{t+1}^{Y, Y}\right)+\pi^{Y} F_{\epsilon, t}^{M}\left(\bar{\epsilon}_{t+1}^{Y, M}\right)
$$

Proof. See appendix.

Proposition 3 highlights the difference between the default behavior of the young and the middle-aged. The default decision depends on total beginning-of-period wealth, 
which combines liquid wealth obtained from last period's asset portfolio and labor income. Since young transitioning to young receive different income than young transitioning to middle-aged, they have different default thresholds.

\subsection{Financial Intermediary}

The financial intermediary is a publicly traded firm in a competitive financial market that maximizes the market value of its equity, which is owned in equilirium by the middle aged generation. It makes mortgages and issues deposits and equities backed by these mortgages. The intermediary starts period $t$ with inside equity $e_{t}$. It must pay a dividend $\tau e_{t}$ each period, so that it does not save its way out of financial constraints over time. It can raise outside equity $I_{t}$ at a $\operatorname{cost} C\left(I_{t}, \bar{Y}_{t}\right)=\frac{\chi}{\bar{Y}_{t}} I_{t}^{2}$. Further, the intermediary faces a regulatory capital constraint that its inside equity can never be less than some fraction $\bar{e}$ of the value of its assets, ensuring its deposits are riskless. Its mortgage lending is financed by the inside equity it does not pay out, newly issued equity, and deposits.

Mortgages provided by the intermediary are priced competitively, so that the intermediary makes zero economic profits from each loan. The present value of cash flows paid by a borrower (valued with the intermediary's pricing kernel) therefore determines how much the intermediary is willing to lend. This is true for mortgages at any degree of leverage and made to any household, so borrowers naturally face a menu of mortgage contracts from which to choose. If $M_{t, t+1}^{I}$ is the intermediary's pricing kernel (derived in the appendix) at time $t$ for valuing cash flows paid at time $t+1$, a mortgage that pays $\delta_{m}$ will induce the intermediary to lend $l_{m}$ at time $t$ equal to

$$
l_{m}=E_{t}\left(M_{t, t+1}^{I} \delta_{m}\right) .
$$

Note that the cash flows an intermediary receives from a mortgage depend both on the mortgage's face value as well as the portfolio choices of the borrower, since these endogenously affect the borrower's incentives to default. A mortgage made to a borrower with

portfolio $\alpha_{t}^{j}$ and face value $m_{t}^{j}$ has present value $q^{j}\left(\alpha_{t}^{j}\right) m_{t}^{j}$, for $j=Y, M$, which intermediaries determine based on the expected payoff of the mortgage.

Although the intermediary could in principle make loans with arbitrary amounts of leverage, the aggregation results derived above drastically simplify the intermediary's problem. We can assume that the intermediary only makes mortages optimally selected by households from the menu of mortgage contracts offered by the intermediary. The intermediary then only optimizes over the total face value $N_{t}^{Y}$ and $N_{t}^{M}$ of mortgages lent 
to each generation. The law of large numbers then implies that all idiosyncratic risk in the payoffs of mortgages made by the intermediary diversifies away.

Based on corollary 1, the payoff to one dollar of face value of this portfolio for the middle generation is

$$
\mathcal{P}_{t+1}^{M}=1-F_{\epsilon, t}^{M}\left(\bar{\epsilon}_{t+1}^{M}\right)+F_{\epsilon, t}^{M}\left(\bar{\epsilon}_{t+1}^{M}\right)(1-\xi)\left(1-\delta_{H}\right) \frac{E_{t}\left(\epsilon^{M} \mid \epsilon^{M}<\bar{\epsilon}_{t+1}^{M}\right) P_{t+1} h_{t}^{M}}{m_{t}^{M}},
$$

where a fraction $\xi$ of the house value is lost when a house of a defaulting borrower is repossessed. Of these losses, a fraction $\xi^{D W L}$ are resource losses to the economy, in the form of nondurables spent on recovering the value of the home.

Similarly, from proposition 3, for the young generation the per-dollar of face value payoff is

$$
\begin{aligned}
\mathcal{P}_{t+1}^{Y}= & \left(1-\pi^{Y}\right)\left(1-F_{\epsilon, t}^{Y}\left(\bar{\epsilon}_{t+1}^{Y, Y}\right)\right)+\pi^{Y}\left(1-F_{\epsilon, t}^{M}\left(\bar{\epsilon}_{t+1}^{Y, M}\right)\right)+(1-\xi)\left(1-\delta_{H}\right) \frac{P_{t+1} h_{t}^{Y}}{m_{t}^{Y}} \times \\
& {\left[\left(1-\pi^{Y}\right) E_{t}\left(\epsilon^{Y} \mid \epsilon^{Y}<\bar{\epsilon}_{t+1}^{Y, Y}\right) F_{\epsilon, t}^{Y}\left(\bar{\epsilon}_{t+1}^{Y, Y}\right)+\pi^{Y} E_{t}\left(\epsilon^{M} \mid \epsilon^{M}<\bar{\epsilon}_{t+1}^{Y, M}\right) F_{\epsilon, t}^{M}\left(\bar{\epsilon}_{t+1}^{Y, M}\right)\right] . }
\end{aligned}
$$

The intermediary is fully owned by middle-aged households, so any net dividends it pays are priced by the consumption Euler equation of the middle aged. Its inside equity at the start of a period is the value of its mortgage portfolio minus its payments to depositors.

$$
e_{t+1}=N_{t}^{Y} \mathcal{P}_{t+1}^{Y}+N_{t}^{M} \mathcal{P}_{t+1}^{M}-D_{t}
$$

The budget constraint of the intermediary is

$$
(1-\tau) e_{t}+I_{t}-C\left(I_{t}, \bar{Y}_{t}\right)+\frac{D_{t}}{1+r_{t}}=N_{t}^{Y} q^{Y}\left(\alpha_{t}^{Y}\right)+N_{t}^{M} q^{M}\left(\alpha_{t}^{M}\right) .
$$

Let $M_{t+1}^{M}$ be the stochastic discount factor of the middle aged, who own the intermediary's equity and price it according to their consumption Euler equation. The full optimization problem of the intermediary is

$$
V^{I}\left(e_{t}, \mathcal{Z}_{t}\right)=\max _{I_{t}, D_{t}, N_{t}^{M}, N_{t}^{Y}} \tau e_{t}-I_{t}+\mathrm{E}_{t}\left[M_{t+1}^{M} V^{I}\left(e_{t+1}, \mathcal{Z}_{t+1}\right)\right]
$$

subject to the budget constraint (11). The regulatory capital constraint requires that the intermediary's leverage is at most $\bar{e}$ for all possible states at time $t+1$. Denote the current state by $\mathcal{Z}_{t}$ and all possible future states conditional on the current state as $z_{t+1} \mid \mathcal{Z}_{t}$. Then 
the solvency constraint leads to the following set of constraints in $t$

$$
e_{t+1} \geq \bar{e}^{Y} N_{t}^{Y} \mathcal{P}^{Y}\left(z_{t+1}\right)+\bar{e}^{M} N_{t}^{M} \mathcal{P}^{M}\left(z_{t+1}\right) \forall z_{t+1} \mid \mathcal{Z}_{t}
$$

or equivalently

$$
\left(1-\bar{e}^{Y}\right) N_{t}^{Y} \mathcal{P}^{Y}\left(z_{t+1}\right)+\left(1-\bar{e}^{M}\right) N_{t}^{M} \mathcal{P}^{M}\left(z_{t+1}\right) \geq D_{t} \forall z_{t+1} \mid \mathcal{Z}_{t}
$$

At time $t$, it suffices to impose the constraint for the worst possible aggregate state in $t+1$ : if the solvency condition is binding for the worst possible payoff of the mortgage portfolio, it will be slack for all higher payoff realizations. This implies that we can define

$$
\underline{z}_{t}=\underset{z_{t+1} \mid \mathcal{Z}_{t}}{\operatorname{argmin}} N_{t}^{Y} \mathcal{P}^{Y}\left(z_{t+1}\right)+N_{t}^{M} \mathcal{P}^{M}\left(z_{t+1}\right),
$$

and impose a single constraint at time $t$

$$
\left(1-\bar{e}^{Y}\right) N_{t}^{Y} \mathcal{P}^{Y}\left(\underline{z}_{t}\right)+\left(1-\bar{e}^{M}\right) N_{t}^{M} \mathcal{P}^{M}\left(\underline{z}_{t}\right) \geq D_{t}
$$

This regulatory capital constraint is only occasionally binding. If the intermediary is sufficiently well capitalized, it has a precautionary incentive to save because of the risk of the constraint binding in the future.

The following proposition verifies what was assumed above about mortgage pricing in order to show that households in each generation make decisions equivalent to those of a representative agent. It follows simply from the fact that there is some pricing kernel that prices mortgages and is therefore general and robust.

Proposition 4. The mortgage pricing functions $q^{j}\left(\alpha_{t}^{j}\right)$ for $j=Y, M$ are homogeneous of degree zero in the wealth of borrowing households, $w_{t}^{j}, j=Y, M$.

Proof. Suppose a household of generation $\mathrm{j}$ chooses a portfolio $\alpha_{t}^{j}$ and mortgage face value $m_{t}^{j}$. Let $\delta_{t}^{j}$ be the cash flows paid by this borrower to the intermediary. If the borrower multiplied each element of its portfolio and its mortgage face value by a constant $k>0$, the intermediary would get cash flows repaid of $k \delta_{t}^{j}$. The intermediary is therefore willing to lend $q^{j}\left(k \alpha_{t}^{j}\right)\left(k m_{t}^{j}\right)=E_{t}\left(M_{t, t+1}^{I} k \delta_{m}\right)=k E_{t}\left(M_{t, t+1}^{I} \delta_{m}\right)=q^{j}\left(\alpha_{t}^{j}\right)\left(k m_{t}^{j}\right)$. This implies $q^{j}\left(k \alpha_{t}^{j}\right)=q^{j}\left(\alpha_{t}^{j}\right)$.

Inspection of the expression in (8) and (9) shows that mortgage payoffs only depend on the default thresholds $\left(\bar{\epsilon}_{t+1}^{Y, Y}, \bar{\epsilon}_{t+1}^{Y, M}, \bar{\epsilon}_{t+1}^{M}\right)$ and the inverse mortgage leverage ratios $P_{t+1} h_{t}^{j} / m_{t}^{j}$. 
From the aggregation results in propositions 1 and 2, these objects are independent of borrower wealth. Intuitively, mortgage pricing depends on mortgage leverage, and the ratio of housing to total wealth. Since all households choose to invest equal shares of wealth in housing and mortgage debt, these ratios are the same for all borrowers within a generation.

\subsection{Equilibrium and Aggregation}

Aggregation. Denote the total beginning-of-period liquid wealth of young that remain young as

$$
\begin{aligned}
\vec{W}_{t}^{Y, Y}=\left(1-\pi^{Y}\right) & {[\underbrace{\left(1-F_{\epsilon, t}^{Y}\left(\bar{\epsilon}_{t}^{Y, Y}\right)\right)\left(\left(1-\delta_{H}\right) \mathrm{E}_{t}\left[\epsilon^{Y} \mid \epsilon^{Y}>\bar{\epsilon}_{t}^{Y, Y}\right] P_{t} h_{t-1}^{Y}-m_{t-1}^{Y}\right)}_{\text {home equity of non-defaulters }}} \\
& +\underbrace{\left(1-\lambda^{Y} F_{\epsilon, t}^{Y}\left(\bar{\epsilon}_{t}^{Y, Y}\right)\right)\left(d_{t-1}^{M}+v Y_{t}^{*}+p_{t}^{Y}\right)}_{\text {other wealth-def. penalty }}] .
\end{aligned}
$$

The home equity of the non-defaulters depends on the conditional expectation $\mathrm{E}_{t}\left[\epsilon^{Y} \mid \epsilon^{Y}>\right.$ $\left.\bar{\epsilon}_{t}^{Y, Y}\right]$, which is the average realization of the idiosyncratic house price shock conditional on not defaulting. Similarly, we define the aggregate wealth of the young that turn middle-aged as

$$
\begin{aligned}
\vec{W}_{t}^{Y, M}= & \pi^{Y}[\underbrace{\left(1-F_{\epsilon, t}^{M}\left(\bar{\epsilon}_{t}^{Y, M}\right)\right)\left(\left(1-\delta_{H}\right) \mathrm{E}_{t}\left[\epsilon^{M} \mid \epsilon^{M}>\bar{\epsilon}_{t}^{Y, M}\right] P_{t} h_{t-1}^{Y}-m_{t-1}^{Y}\right)}_{\text {home equity of non-def. }} \\
& +\underbrace{\left(1-\lambda^{Y} F_{\epsilon, t}^{M}\left(\bar{\epsilon}_{t}^{Y, M}\right)\right)\left(d_{t-1}^{M}+\left((1-v) Y_{t}^{*}+B_{t}^{O}\right) / \pi^{Y}\right)}_{\text {other wealth-def. penalty }}] .
\end{aligned}
$$

Then the aggregate wealth of the young generation is

$$
W_{t}^{Y}=\pi^{Y}\left(\nu Y_{t}^{*}+p_{t}^{Y}\right)+\vec{W}_{t}^{Y, Y}
$$

The first term is the endowment income newly-born households receive. The second 
term is the liquid wealth of previous young and depends on the default decision. Further defining the wealth of the middle aged who do not turn old

$$
\vec{W}_{t}^{M}=\left(1-F_{\epsilon, t}^{Y}\left(\bar{\epsilon}_{t}^{M}\right)\right)\left(\left(1-\delta_{H}\right) \mathrm{E}_{t}\left[\epsilon^{M} \mid \epsilon^{M}>\bar{\epsilon}_{t}^{M}\right] P_{t} h_{t-1}^{M}-m_{t-1}^{M}\right)+\left(1-\lambda^{M} F_{\epsilon, t}^{M}\left(\bar{\epsilon}_{t}^{M}\right)\right) w_{t}^{M, d},
$$

the aggregate wealth of the middle generation is

$$
W_{t}^{M}=\vec{W}_{t}^{Y, M}+\left(1-\pi^{M}\right) \vec{W}_{t}^{M}
$$

Finally, the aggregate beginning-of-period wealth of the old is

$$
W_{t}^{O}=\pi^{M} \vec{W}_{t}^{M} .
$$

The rebate terms $U_{t}^{j}, j=Y, M, O$, consist of bankruptcy costs that are not resource costs to the economy, and monetary default penalties. The total bankruptcy costs are

$$
\begin{aligned}
U_{t}^{\zeta}=\xi P_{t} & {\left[F_{\epsilon, t}^{M}\left(\bar{\epsilon}_{t}^{M}\right) \mathrm{E}_{t}\left[\epsilon^{M} \mid \epsilon^{M}<\bar{\epsilon}_{t}^{M}\right] h_{t-1}^{M}\right.} \\
& \left.+\left(\left(1-\pi^{Y}\right) F_{\epsilon}^{M}\left(\bar{\epsilon}_{t}^{Y, Y}\right) \mathrm{E}_{t}\left[\epsilon^{Y} \mid \epsilon^{Y}<\bar{\epsilon}_{t}^{Y, Y}\right]+\pi^{Y} F_{\epsilon}^{Y}\left(\bar{\epsilon}_{t}^{Y, M}\right) \mathrm{E}_{t}\left[\epsilon^{M} \mid \epsilon^{M}<\bar{\epsilon}_{t}^{Y, M}\right]\right) h_{t-1}^{Y}\right],
\end{aligned}
$$

and a fraction $\xi^{D W L}$ of these are true resource costs. The remaining fraction $1-\xi^{D W L}$ consists of factor payments to the actors involved in the bankruptcy process and is rebated to households.

Monetary default penalties are

$$
U_{t}^{\lambda}=\lambda^{Y}\left(1-\pi^{Y}\right) F_{\epsilon, t}^{Y}\left(\bar{\epsilon}_{t}^{Y, Y}\right) w_{t}^{Y Y, d}+\lambda^{Y} F_{\epsilon, t}^{M}\left(\bar{\epsilon}_{t}^{Y, M}\right)\left(\pi^{Y} d_{t-1}^{M}+(1-v) Y_{t}^{*}+B_{t}^{O}\right)+\lambda^{M} F_{\epsilon, t}^{M}\left(\bar{\epsilon}_{t}^{M}\right) w_{t}^{M, d} .
$$

The sum of both rebate terms, $U_{t}=\left(1-\xi^{D W L}\right) U_{t}^{\xi}+U_{t}^{\lambda}$, is included in the payoff of the endowment along with the output of the economy $Y_{t}$, so the total payoff is

$$
Y_{t}^{*}=Y_{t}+U_{t}
$$

Equilibrium. Market clearing for mortgage debt requires that intermediaries purchase the full portfolio of mortgages of both borrowing generations:

$$
\begin{aligned}
N_{t}^{Y} & =m_{t}^{Y}, \\
N_{t}^{M} & =m_{t}^{M} .
\end{aligned}
$$


Market clearing for housing capital requires that

$$
h_{t}^{Y}+h_{t}^{M}=\bar{H}_{t}
$$

and the rental market needs to clear within each generation

$$
\begin{aligned}
s_{t}^{Y} & =h_{t}^{Y} \bar{Y}_{t}, \\
s_{t}^{M} & =h_{t}^{M} \bar{Y}_{t} .
\end{aligned}
$$

Market clearing for intermediary liabilities requires

$$
\begin{aligned}
D_{t} & =d_{t}^{Y}+d_{t}^{M}, \\
b_{t}^{M} & =1 .
\end{aligned}
$$

Shares to the endowment income of the young are in unit supply such that

$$
\eta_{t}^{Y}=1
$$

Finally, market clearing for non-durables requires that

$$
Y_{t}=c_{t}^{Y}+c_{t}^{M}+c_{t}^{O}+C\left(I_{t}, \bar{Y}_{t}\right)+\xi^{D W L} U_{t}^{\tau} .
$$

An equilibrium is a set of prices and allocations such that all 3 generations and the intermediary solve their optimization problems above (equations 1,2,4, and 12) and all markets clear. The behavior of each generation depends on their own wealth as well as on prices common to all agents, and the behaviour of the intermediary depends on its initial inside equity. These prices are also influenced by the cyclical output shock $\tilde{Y}_{t}$ and the binary shock to the distribution of idiosyncratic house price shocks. Because the wealth of all agents sum up to the total wealth in the economy, we need only track three endogenous state variables $W_{t}^{Y}, W_{t}^{M}$ and $e_{t}$ in addition to the two exogenous state variables in Markovian equilibrium. 


\section{Calibration and Solution Method}

\subsection{Parameterization}

We calibrate the model to annual U.S. data. Table 1 lists the parameter values. As indicated in the table, several parameters are directly set to external estimates. The remaining parameters are chosen jointly so that simulated moments from the model's stationary distribution match a set of corresponding moments in the data.

Growth Rate and Productivity shocks. We calibrate the trend growth rate and productivity shocks based on real disposable income per capita from 1929-2017. The annual growth rate is exactly $2 \%$. The standard deviation and autocorrelation of the cyclical HP-filtered series are $2.7 \%$ and $45 \%$, respectively. We convert the continuous AR(1) productivity process to a 3-state Markov chain using the Rouwenhorst (1995) method. The aggregate endowment income per year is normalized to 1, as is the fixed housing stock $\bar{H}$.

Preferences and Life-Cycle. Risk aversion is set to a standard value of 2 . We choose the discount factor $\beta$ to match the deposit rate in the model to the annualized real yield of 3-month treasury bills, from 1951-2017, which is $0.9 \%$. Several preference and lifecycle related parameters are chosen to match moments from the Survey of Consumer Finances (SCF). We compute means for the target moments from SCF waves between 1995-2016 using SCF sampling weights, and calculate averages of the means to arrive at a single target moment. Following Wong (2018), we categorize households by age of the household head, with the young being 25-34 years of age, the middle-aged between 35-64, and the old 65 and older. We set the weight on housing in the Cobb-Douglas consumption aggregator to 0.16 to match the average housing wealth-to-income ratio of middle-aged households in the SCF, which comes out to 2.1. We pick the preference parameter $\psi^{M}$ to match the liquidity premium estimated by Krishnamurthy and Vissing-Jorgensen (2012) of $70 \mathrm{bp}$ for the middle-aged. ${ }^{5}$ For young households, we choose $\psi^{Y}$ to match the ratio of liquid wealth-to-income for young households from the SCF of $13 \%$.

The probabilities of transitioning from young to middle-aged, and from middle-aged to old, are set to match the aggregate ratio of wealth over income for young and middle-

\footnotetext{
${ }^{5}$ We calculate the liquidity premium in the model as the difference of a counterfactual risk free rate that does not provide any liquidity services and the deposit rate.
} 
Table 1: Parameter choices

\begin{tabular}{|c|c|c|c|c|c|}
\hline Parameter & & Value & Target & Data & Model \\
\hline \multicolumn{6}{|c|}{ TFP } \\
\hline Growth rate & $g$ & 0.02 & Average growth rate income p.c. & & \\
\hline Income shocks std.dev. & $\sigma^{Y}$ & 0.027 & Std. dev. HP-filtered income p.c. & & \\
\hline Income shocks AC & $\rho^{Y}$ & 0.45 & Autocorrelation HP-filtered income p.c. & & \\
\hline \multicolumn{6}{|c|}{ Preferences } \\
\hline Risk aversion (1/IES) & $\gamma$ & 2 & standard & & \\
\hline Patience & $\beta$ & 0.9 & Avg. real rate on 3-month treasuries & $90 \mathrm{bp}$ & 130bp \\
\hline Weight on housing & $\theta$ & 0.16 & Housing wealth/income (SCF) & 2.14 & 2.11 \\
\hline Liquidity preference $\mathrm{M}$ & $\psi^{M}$ & 0.02 & Liquidity premium KVJ & $70 \mathrm{bp}$ & $78 \mathrm{bp}$ \\
\hline Liquidity preference $Y$ & $\psi^{Y}$ & 0.002 & Money-like assets of young/income (SCF) & 0.13 & 0.13 \\
\hline \multicolumn{6}{|c|}{ Life-cycle } \\
\hline Transition prob Y & $\pi^{Y}$ & 0.14 & Wealth/income young (SCF) & 1.6 & 1.68 \\
\hline Transition prob M & $\pi^{M}$ & 0.25 & Wealth/income middle-aged (SCF) & 5.2 & 5.63 \\
\hline Income share of young & $v$ & 0.32 & Consumption share young (Wong) & 0.32 & 0.31 \\
\hline Discount of old & $\beta^{O}$ & 0.15 & Wealth old/ wealth middle-aged (SCF) & 0.18 & 0.18 \\
\hline Bequest parameter & $\phi$ & 35 & Consumption share old (Wong) & 0.11 & 0.12 \\
\hline \multicolumn{6}{|c|}{ Housing and mortgages } \\
\hline Forced maintenance & $\delta_{H}$ & 0.025 & Housing depreciation (BLS) & & \\
\hline Idiosyncratic shock std.dev Y,M & $\sigma_{\epsilon}^{0}$ & 0.22 & Foreclosure rate (\%) & 1.7 & 1.4 \\
\hline Idiosyncratic shock std.dev Y,M & $\sigma_{\epsilon}^{1}$ & 0.25 & Foreclosure rate, crisis (\%) & 4.8 & 5.2 \\
\hline Trans. prob. $\sigma_{\epsilon}^{0} \rightarrow \sigma_{\epsilon}^{1}$ & $\Gamma_{1,2}$ & 0.05 & $\%$ periods in housing recession & & 0.2 \\
\hline Trans. prob. $\sigma_{\epsilon}^{1} \rightarrow \sigma_{\epsilon}^{0}$ & $\Gamma_{2,1}$ & 0.2 & Duration (years) housing recession & & 4.5 \\
\hline Recourse after default $Y$ & $\lambda^{Y^{1}}$ & 0.015 & LTV of young (SCF) & 0.65 & 0.62 \\
\hline Recourse after default M & $\lambda^{M}$ & 0.005 & LTV of middle-aged (SCF) & 0.40 & 0.39 \\
\hline Foreclosure loss to bank & & 0.3 & Charge-off rate mortgages (\%) & 0.5 & 0.6 \\
\hline Foreclosure DWL fraction & $\xi^{D W L}$ & 0.5 & Anenberg \& Kung (2014) & & \\
\hline \multicolumn{6}{|c|}{ Intermediary } \\
\hline Capital requirement & $\bar{e}^{M}$ & 0.01 & Basel requirement Agency MBS & & \\
\hline Capital requirement & $\bar{e}^{Y}$ & 0.08 & Basel requirement Mortgage Loans & & \\
\hline Target payout ratio & $\tau$ & 0.1 & Effective payout rate (Baron) & 7.3 & 4.6 \\
\hline Equity issuance cost & $\chi$ & 200 & Equity issuance rate (Baron) & 3.5 & 5.2 \\
\hline
\end{tabular}

Parameters without corresponding data and model moments in the two rightmost columns are set directly based on external data. All other parameters are jointly chosen to match the target moments listed in the table as closely as possible. 
aged households in the SCF, respectively. ${ }^{6}$ The transition parameters also have implications for the population mass of households in each age group. However, as this aspect of the model is somewhat stylized, we choose to match the intergenerational wealth distribution rather than age or wealth at the level of individual households. The share of the aggregate endowment received by the young, $v$, is set to $33 \%$ to match the consumption share of the young, which Wong (2018) estimates to be $32 \%$ of aggregate consumption. Similarly, we choose the bequest utility parameter to match the consumption share of the old at $12 \%$, also as reported by Wong (2018). Naturally, the middle-aged consume the remaining $56 \%$. To match both consumption of the old, and their wealth relative to that of the middle-aged, we allow for the additional discount factor $\beta^{O}$.

Housing and Mortgages. We set the forced maintenance of housing $\delta_{H}$ to match depreciation of residential fixed assets based on the BEA fixed asset tables. Idiosyncratic house price dispersion follows a two-state Markov Chain with transition matrix $\Gamma$, with state 0 indicating normal times, and state 1 indicating elevated housing risk. The probability of staying in the normal state in the next year is $95 \%$ and the probability of staying in the crisis state in the next quarter is $80 \%$. Under these parameters, the economy spends $80 \%$ of the time in the normal state and $20 \%$ in the high housing risk state, and the average duration of the high risk state is 4.5 years. These transition probabilities are independent of the aggregate endowment state. The low uncertainty state has $\bar{\sigma}_{\epsilon, 0}=0.22$ and the high uncertainty state has $\bar{\sigma}_{\omega, 1}=0.38$. We use the same values for idiosyncratic housing risk of young and middle-aged households. These numbers allow the model to match an average mortgage default rate of $1.4 \%$ per year unconditionally and of $5.4 \%$ per year in housing recessions, which are periods defined by low endowment growth and high housing risk. In the data, the average mortgage foreclosure rate is $1.7 \%$ unconditionally, and peaks at $5 \%$ in $2011 .{ }^{7}$ Combined with a foreclosure loss for banks of $30 \%$, the model generates a loss-given-default rate of $40 \%$, and thus an overall loss rate on banks' mortgage portfolio $0.6 \%$ unconditionally and $2.4 \%$ in housing recessions, in line with data on charge-off rates on residential loans at US banks for the 1991-2017 period.

Given the housing risk parameters, we choose the pecuniary default penalties $\lambda^{Y}$ and $\lambda^{M}$ to match mortgage leverage of young and middle-aged households in the SCF. Holding fixed other parameters, households choose lower leverage at a higher level of $\lambda$. A

\footnotetext{
${ }^{6}$ To be clear, we do not match the average of the wealth-to-income ratio of individual households. Rather, we compute the ratio by dividing the total wealth of all sample households in the respective age group by their total income.

${ }^{7}$ Data are from Mortgage Bankers Association for 1979-2017.
} 
value of $\lambda^{Y}=1.5 \%$ delivers young leverage of $63 \%$, and $\lambda^{M}=0.5 \%$ gives middle-aged leverage of $40 \%$. Even though we make it more costly for the young to default, they still choose higher leveragethan the middle-aged because of the severity of their borrowing constraints.

Intermediary. We set the equity capital requirements for the intermediary sector based on Basel risk-weighted regulatory requirements for mortgage assets. Since mortgages of young households are far riskier than those of middle-aged borrowers in equilibrium, we assign $100 \%$ risk weight to these assets, which combined with a simple equity ratio requirement of $8 \%$ yields $\bar{e}^{Y}=0.08$. We calibrate the capital requirement for middle-age mortgages, which are close to risk-free, to the risk weight of GSE-issued mortgage backed securities of $20 \%$, yielding $\bar{e}^{M}=0.016 .{ }^{8}$ We calibrate the remaining two parameters of the intermediary objective based on evidence in Baron (2018). We set $\tau$ to match the effective payout rate of banks, and $\chi$ to target the equity issuance rate, both measured as a fraction of book equity.

\subsection{Solution Method}

We solve the model numerically using a global projection method. The two aggregate exogenous state variables of the economy are the cyclical component of the endowment, and the time-varying cross-sectional dispersion of idiosyncratic housing shocks. Both shocks are jointly approximated by a discrete-time Markov chain. The model features four endogenous aggregate state variables, which span the wealth distribution across the different optimizing agents. They are aggregate wealth of the young, middle-aged, and old, and intermediary equity. Since the wealth of all agents has to add up to aggregate tradable wealth, we only need to keep track of any three of these four endogenous state variables when computing the model.

The solution technique involves approximating the unknown functions that characterize the equilibrium of the economy over the domain of the state variables. The Appendix summarizes the set of equations and unknowns that fully characterize the equilibrium. For details on the solution method, see Elenev, Landvoigt, and Van Nieuwerburgh (2018).

\footnotetext{
${ }^{8}$ These capital requirements for portfolio mortgages and agency MBS have not changed since Basel I regulations.
} 


\section{Results}

We perform a long simulation of the calibrated model and report both the average behaviour of the economy as well as conditional on an expansion, recession, and housing recession. In addition, we the model for three quantitative counterfactual exercises. First, we compare the behaviour of the economy in regular productivity-driven recessions and in "housing recessions" that feature both low endowment realizations and high house price shock dispersion. Second, we show how the economy responds to an unanticipated $30 \%$ drop in intermediary capital. Finally, we consider the effects of two unanticipated shocks, (i) an increased demand for safe assets produced by intermediaries, and in a second simulation add (ii) a (perceived) reduction in housing risk and show how they lead to a credit boom and increase the severity of future financial crises.

\subsection{Properties of Ergodic Distribution}

Borrowers. Table 2 report means from the ergodic distribution of the model. Young households own $28 \%$ of the total housing stock, while the middle-aged generation own the remaining $72 \%$ (lines 1 and 2). Even though the middle-aged own more housing, they have significantly less mortgage debt, with a LTV ratio of 39\% (line 4), as compared to $63 \%$ for young households (line 4). Since the middle-aged also hold the majority of deposits issued by banks, as well as bank equity, they are substantially wealthier than the young (lines 4-5). Both types of households face the same idiosyncratic housing risk. Therefore, the young have much higher default risk as result of higher mortgage leverage: the average mortgage default rate of young borrowers is $3.26 \%$, whereas it is only $0.18 \%$ for the middle-aged (lines 6-7). Why do young households take on so much higher leverage than the old, despite facing the same amount of mortgage risk? This is because young households are financially constrained, in the sense that they expect greater income and wealth in future life-cycle phases. Higher mortgage leverage for a given house size allows them to trade the possibility of greater future mortgage payments in exchange for more consumption in the present. Although there are costs of mortgage default, they are willing to bear some of these costs in exchange for moving consumption forward in time.

The average default rate for lenders holding a diversified portfolio of young and middleaged mortgages is $1.36 \%$, which results in an effective loss rate on mortgage assets of $0.57 \%$ (lines 9-10). How do leverage and defaults vary of the business and housing cycle? Leverage of both types of borrowers is highest in regular recessions, as default risk in those periods is not much higher than during expansions, and households use their 
home equity for consumption smoothing. In particular, young household leverage rises to $67.5 \%$ in regular recessions. During housing recessions, leverage of all borrowers declines as default rates spike, and lenders raise interest rates. The default rate of middleaged households rises to $1.2 \%$ on average, while that of young borrowers jumps to $12.3 \%$. As a result, the average default rate rises to $5.5 \%$, and intermediaries make credit losses of $2.3 \%$ of their portfolio per year in housing recessions.

Banks. Total mortgages assets are roughly equal in size to endowment income at 0.96 (line 12). Banks fund on average $6.75 \%$ of their assets with equity (line 13), and the remaining fraction with deposits, implying a total average deposit base of 0.89 (line 11). About $45 \%$ of bank equity represents a buffer that banks must hold to satisfy their solvency constraint (line 14). This buffer is largest during expansions at 53\%, when the difference between the current state (expansion) and the worst possible future state (housing recession) is largest. The banking sector shrinks substantially during housing recessions: mortgage assets and deposits decline by almost $14 \%$ and $13 \%$, relative to their unconditional average. The equity ratio drops down to $3.8 \%$, as banks suffer large losses. Banks' equity buffer during housing recessions is depleted to $6.2 \%$ of total equity, which is sufficient to satisfy the solvency constraint: once the economy transitioned into a housing recession, there is little downside risk going forward.

These equity dynamics are reflected in the fraction of periods during which the intermediary's solvency constraint is binding (line 15). It is binding $100 \%$ of expansions years, since during these periods banks expand lending and build equity through retaining earnings. Expansions are also periods of high payouts to shareholders (line 16), with a payout rate of $4.36 \%$. The constraint is slack $33 \%$ of periods during regular recessions, as lending contracts and banks only suffer moderate losses. The constraint binds in $90 \%$ of housing recession periods. In these periods, banks raise new equity, reducing the payout rate to $-5.34 \%$ to recover from mortgage losses.

While the external expected excess return (EER) to bank equity is relatively low at $0.92 \%$ (line 17), the internal EER is much higher at $7.9 \%$. The difference shows that making mortgage loans to young households, while borrowing "cheap" deposits from middle-aged is a very profitable business for banks. However, due to the equity-related frictions, there is a large wedge between internal and external equity. Forward-looking profit opportunities for banks become largest during housing recessions, with the EER on internal equity rising to $11.4 \%$. This reflects countercyclical risk compensation: once the economy has arrived in a housing recession, recovery of house prices and mortgage 
Table 2: Means of ergodic distribution

\begin{tabular}{|c|c|c|c|c|}
\hline & Uncond. & Exp. & Rec. & Housing Rec. \\
\hline & \multicolumn{4}{|c|}{ Households } \\
\hline 1. Housing $Y$ & 0.279 & 0.280 & 0.275 & 0.270 \\
\hline 2. Housing $\mathrm{M}$ & 0.721 & 0.720 & 0.725 & 0.730 \\
\hline 3. Leverage $Y$ & $62.90 \%$ & $62.97 \%$ & $67.50 \%$ & $60.49 \%$ \\
\hline 4. Leverage $\mathrm{M}$ & $38.99 \%$ & $39.01 \%$ & $41.88 \%$ & $37.43 \%$ \\
\hline 5. Deposits $Y$ & 0.041 & 0.043 & 0.040 & 0.035 \\
\hline 6. Deposits M & 0.852 & 0.874 & 0.877 & 0.752 \\
\hline 7. Default rate $Y$ & $3.26 \%$ & $1.25 \%$ & $2.71 \%$ & $12.30 \%$ \\
\hline 6. Default rate $\mathrm{M}$ & $0.18 \%$ & $0.00 \%$ & $0.01 \%$ & $1.24 \%$ \\
\hline 9. Default rate (dollar weighted) & $1.36 \%$ & $0.48 \%$ & $1.04 \%$ & $5.45 \%$ \\
\hline \multirow[t]{2}{*}{ 10. Loss rate (dollar weighted) } & $0.57 \%$ & $0.19 \%$ & $0.40 \%$ & $2.39 \%$ \\
\hline & \multicolumn{4}{|c|}{ Intermediary } \\
\hline 11. Total deposits & 0.894 & 0.917 & 0.916 & 0.787 \\
\hline 12. Total mortgage assets & 0.964 & 0.994 & 0.994 & 0.831 \\
\hline 13. Equity ratio (\% of assets) & $6.75 \%$ & $7.36 \%$ & $7.46 \%$ & $3.80 \%$ \\
\hline 14. Equity buffer (\% of equity) & $45.02 \%$ & $53.22 \%$ & $50.35 \%$ & $6.22 \%$ \\
\hline 15. Fraction solvency constr binds & $90.88 \%$ & $100.00 \%$ & $67.91 \%$ & $89.88 \%$ \\
\hline 16. Net payout rate & $2.85 \%$ & $4.36 \%$ & $4.30 \%$ & $-5.34 \%$ \\
\hline 17. External equity EER & $0.92 \%$ & $0.89 \%$ & $0.89 \%$ & $1.07 \%$ \\
\hline \multirow[t]{2}{*}{ 18. Internal equity EER } & $7.91 \%$ & $7.94 \%$ & $6.12 \%$ & $11.39 \%$ \\
\hline & \multicolumn{4}{|c|}{ Prices } \\
\hline 19. House Price & 2.114 & 2.175 & 2.032 & 1.904 \\
\hline 20. Deposit rate & $1.37 \%$ & $1.09 \%$ & $5.15 \%$ & $1.54 \%$ \\
\hline 21. Convenience yield & $0.78 \%$ & $0.75 \%$ & $0.69 \%$ & $0.93 \%$ \\
\hline 22. Mortgage spread Y & $2.69 \%$ & $2.30 \%$ & $2.33 \%$ & $4.77 \%$ \\
\hline 23. Mortgage spread M & $0.07 \%$ & $0.06 \%$ & $0.09 \%$ & $-0.03 \%$ \\
\hline 24. Mortgage Y EER & $1.24 \%$ & $1.32 \%$ & $1.00 \%$ & $1.56 \%$ \\
\hline \multirow[t]{2}{*}{ 25. Mortgage M EER } & $0.00 \%$ & $0.03 \%$ & $0.05 \%$ & $-0.23 \%$ \\
\hline & \multicolumn{4}{|c|}{ Welfare } \\
\hline 26. Consumption $\mathrm{Y}$ & 0.288 & 0.292 & 0.275 & 0.278 \\
\hline 27. Consumption $\mathrm{M}$ & 0.539 & 0.545 & 0.524 & 0.521 \\
\hline 28. Consumption $\mathrm{O}$ & 0.118 & 0.119 & 0.112 & 0.115 \\
\hline 29. Consumption gr vol, $\mathrm{Y}$ & $3.07 \%$ & $2.81 \%$ & $2.60 \%$ & $2.74 \%$ \\
\hline 30. Consumption gr vol, $\mathrm{M}$ & $2.25 \%$ & $2.09 \%$ & $1.94 \%$ & $2.11 \%$ \\
\hline 31. Bankruptcy DWL & 0.002 & 0.001 & 0.001 & 0.006 \\
\hline 32. Issuance DWL & 0.002 & 0.002 & 0.002 & 0.002 \\
\hline 33. Housing maintenance & 0.053 & 0.054 & 0.051 & 0.048 \\
\hline
\end{tabular}

The table reports averages from a long simulation (10,000 periods) of the benchmark model. First column: unconditional average, second column: expansions (high or average endowment), third column: regular recessions (low endowment), and fourth column: housing recessions (low endowment, high housing risk $\sigma_{\epsilon}^{1}$ ). 
debt to normal levels involves a large expansion of banking. During the recovery from housing recession, young households that were forced to deleverage have high demand for mortgage debt, and banks can earn large excess returns going forward (line 24).

Prices. The model generates substantial house price fluctuations, close to the volatility of aggregate house prices in the data. House prices are 13\% lower during housing recessions than during expansions (line 19). The deposit rate is countercyclical (line 20), a feature our model has in common with other endowment economies that have meanreverting shocks and agents with a low intertemporal elasticity of substitution: during recessions, agents expect higher income in the future and would like to move this future income to the present, reducing savings demand. To clear the deposit market, the interest rate needs to rise. Interestingly, the interest rate rises by much less during housing recessions than during regular recessions. This is because in housing recessions deposit supply by banks also shrinks. The convenience yield contained in deposit rates is $0.78 \%$ on average (line 21), and rises in housing recessions when deposits become scarce. Mortgage spreads for young households are much higher at $2.7 \%$ than those of middle-aged households at $0.07 \%$, primarily due to large differences in risk (lines 22-23). At $1.24 \%$, almost half of the mortgage spread for the young is a risk premium (line 24). The risk premium on young mortgages is highest during housing recessions.

Consumption. The consumption distribution reflects the income and wealth distribution between generations (lines 26-28). Consumption fluctuations are mainly driven by endowment shocks, with aggregate consumption in regular and housing recessions being roughly equal. Larger deadweight losses from bankruptcies in housing recessions are offset by less expenditure on housing maintenance due to lower house prices (lines 31,33). While consumption growth of the young is more volatile than endowment income $(3.07 \%$ vs. $2.7 \%)$, middle-aged consumption growth vol is lower $(2.25 \%)$. The young prioritize asset accumulation though levered exposure to housing over consumption smoothing.

\subsection{Response to productivity and housing risk shocks}

Next, we will examine the how the economy reacts to endowment (productivity) and housing risk shocks. Figure 1 shows impulse response functions to a pure negative endowment shock (blue) and the combination of a negative endowment shock and a housing risk shock (red). By construction, the blue and red lines coincide in the top left panel 
of Figure 1. However, as can be seen from the second panel in the top row, housing risk spikes during housing recessions, and reverts to normal levels over ten years on average. ${ }^{9}$ Consumption of agents is primarily driven by endowment shocks, and the differences in consumption responses are small.

Figure 1: Regular vs. housing Recession (part 1)
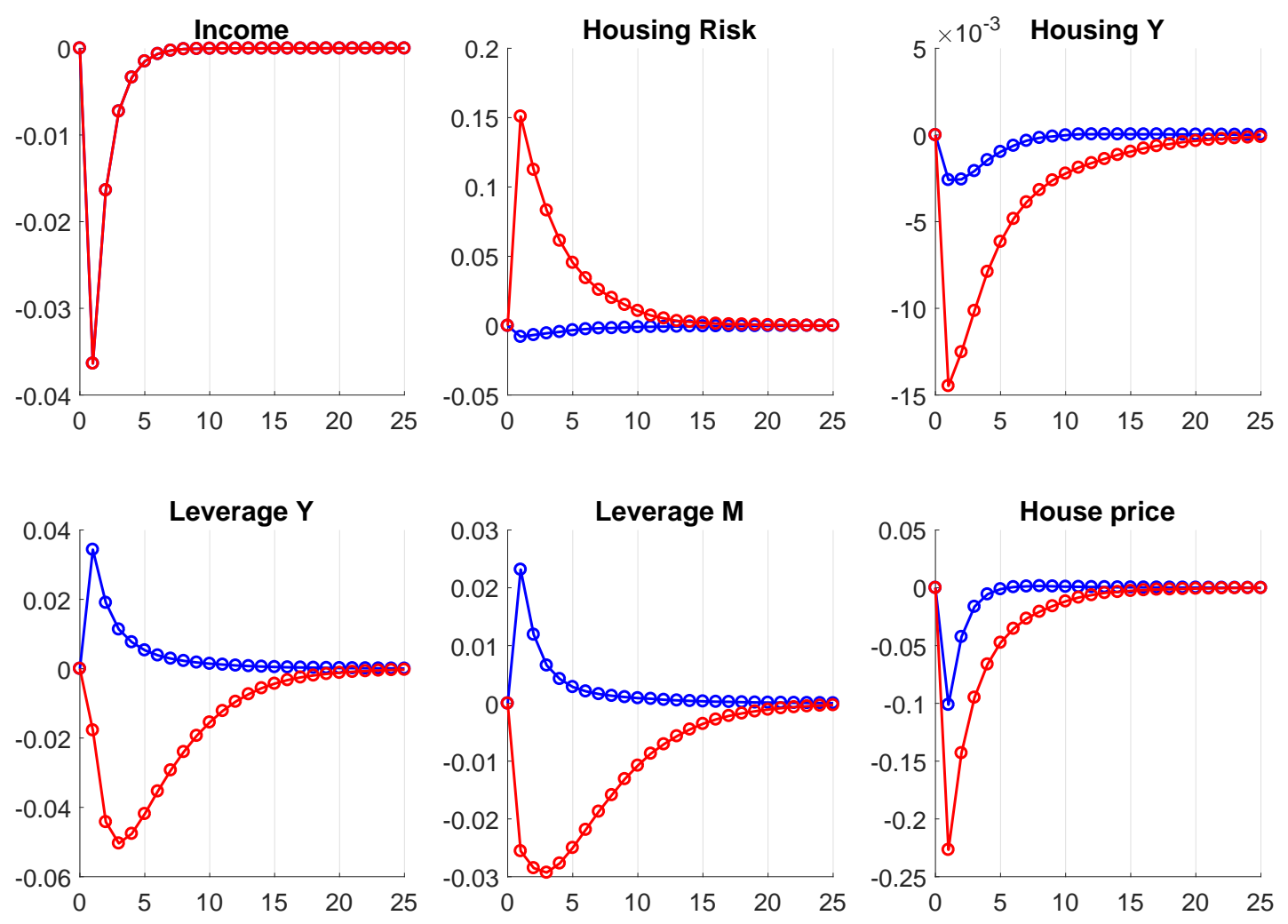

Blue: regular recession, Red: housing recession. The generalized IRF plots are created by simulating the economy 10,000 times for 25 years, and plotting the average path of variables. The simulations are initialized at the ergodic distribution of the endogenous states, the mean income level, and in the low-housingrisk state $\bar{\sigma}_{\epsilon, 0}$. The plots indicate deviations from the unconditional path in levels.

However, as can be seen in the bottom right panel, housing recessions cause a large reallocation of housing capital from young to middle-aged borrowers. This is mainly due to a strong wealth effect: young households have much greater exposure to house price risk than middle-aged households due to their high leverage. As house prices drop in housing recessions, young households lose more wealth than middle-aged, and sell housing capital.

We can see the large drop in house prices during housing recession in the top left

\footnotetext{
${ }^{9}$ Recall that $\sigma_{\epsilon}$ is a two-state Markov chain with the average duration of a high-housing-risk episode being 4.5 years.
} 
Figure 2: Regular vs. housing Recession (part 2)
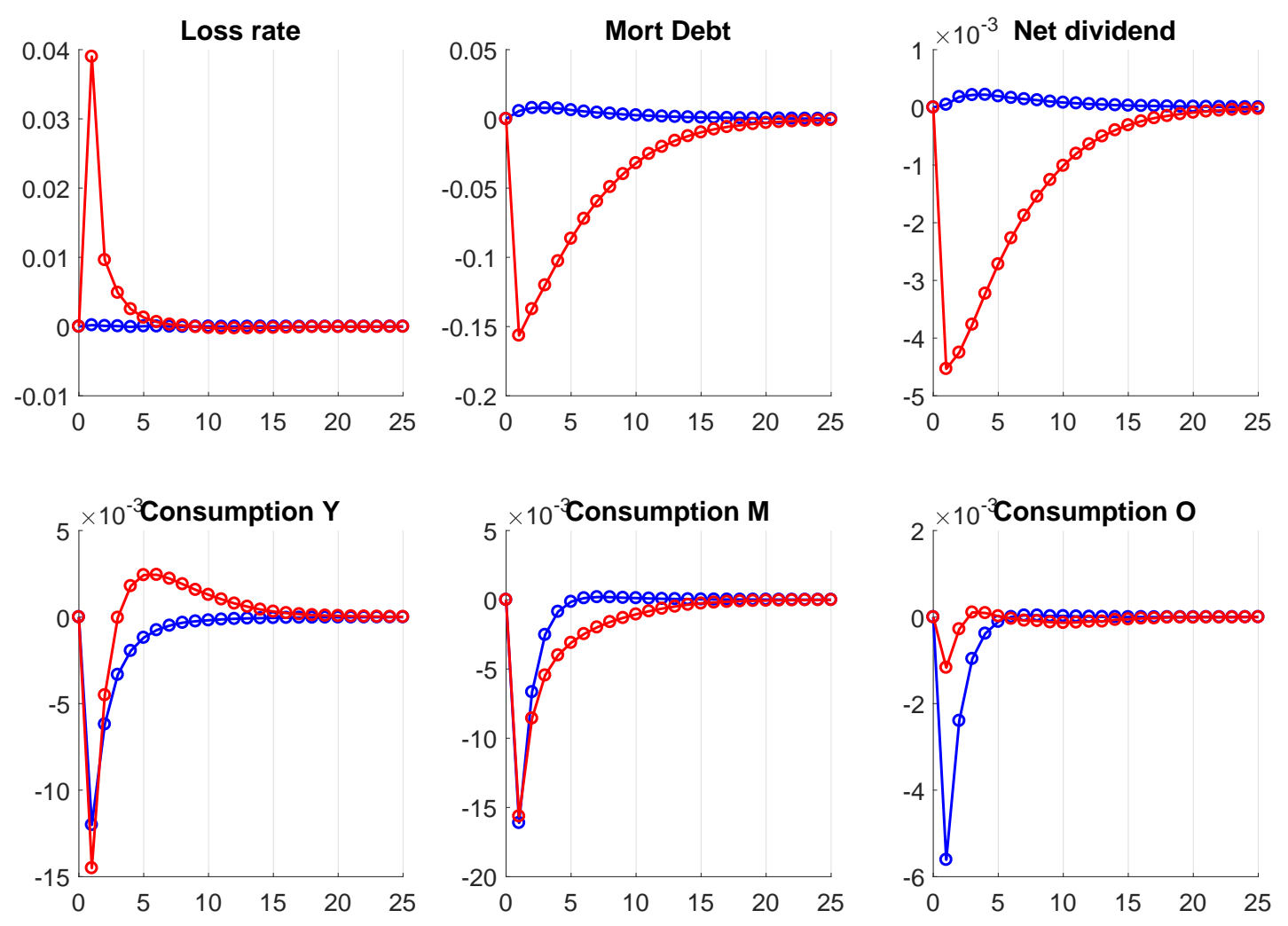

Blue: regular recession, Red: housing recession. The generalized IRF plots are created by simulating the economy 10,000 times for 25 years, and plotting the average path of variables. The simulations are initialized at the ergodic distribution of the endogenous states, the mean income level, and in the low-housingrisk state $\bar{\sigma}_{\epsilon, 0}$. The plots indicate deviations from the unconditional path in levels.

panel of figure 2. While households increase leverage in regular recessions, they reduce leverage in housing recessions. Despite the sharp deleveraging of young borrowers, the mortgage spread they face spikes during housing recessions, while it remains flat in regular recessions. Middle-aged households reduce leverage so aggressively relative to the baseline that their equilibrium mortgage spread declines. The difference in responses of young and middle-aged households highlights the differing degrees of financial constraints the two generations face. Young households have large exposure to housing risk and low wealth. When mortgage borrowing becomes more expensive, they are not only forced to delever, but also shed housing capital. The more wealthy middle-aged are less affected by reduced mortgage borrowing. They simply re-optimize their portfolio to be less levered, and buy housing capital cheaply from the young. As house prices recover, the earn large returns. During regular recessions, the deposit rate exhibits the typical properties of the riskfree rate in an endowment economy: it rises sharply to increase sav- 
ings demand. However, the rate drops in housing recessions.

Figure 3: Regular vs. housing Recession (part 3)
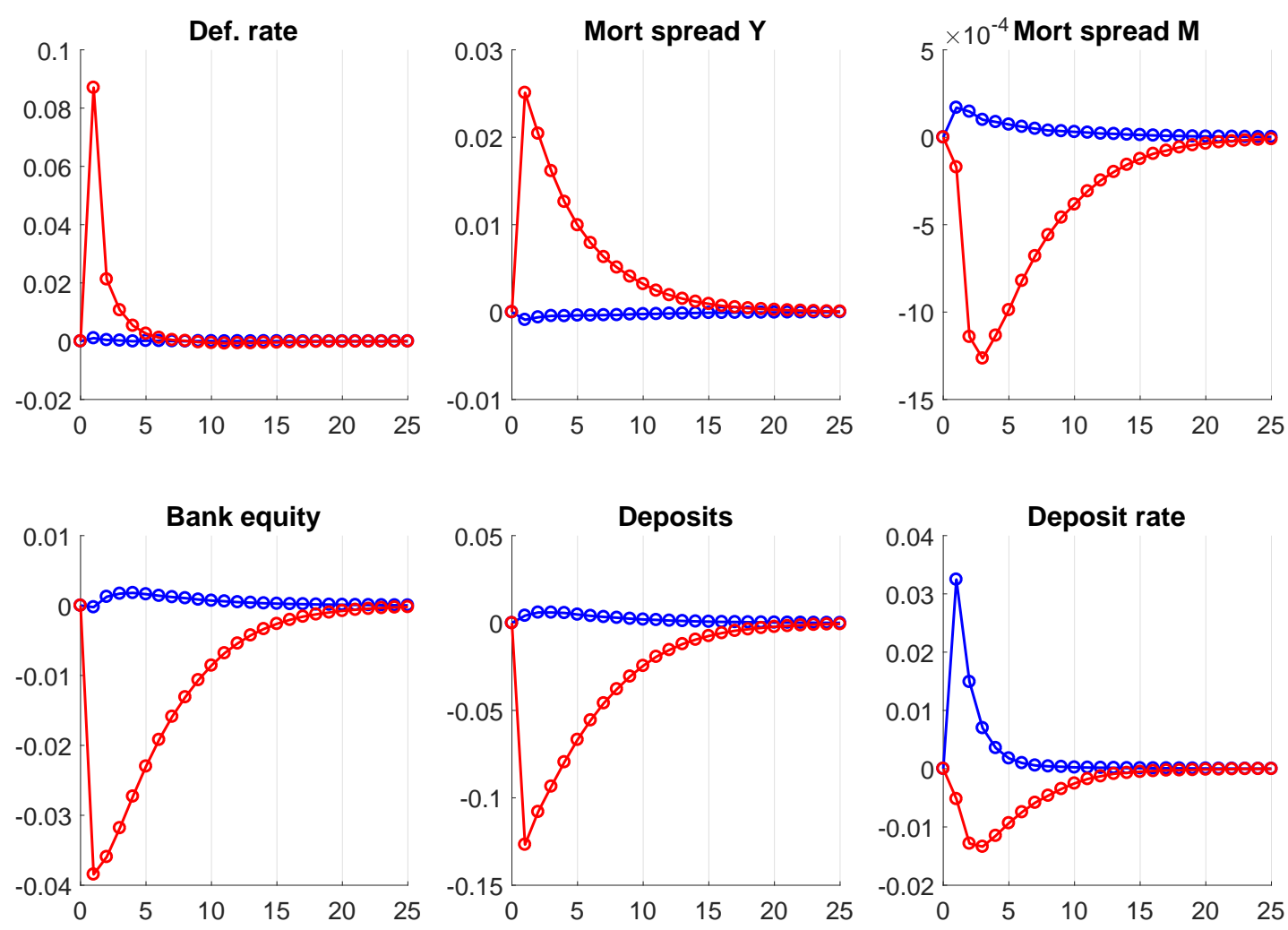

Blue: regular recession, Red: housing recession. The generalized IRF plots are created by simulating the economy 10,000 times for 25 years, and plotting the average path of variables. The simulations are initialized at the ergodic distribution of the endogenous states, the mean income level, and in the low-housingrisk state $\bar{\sigma}_{\epsilon, 0}$. The plots indicate deviations from the unconditional path in levels.

The reason for this difference can be seen in figure 3. In housing recessions, the mortgage default rate (top left) and the loss rate on the mortgage portfolio of banks (top middle) spike sharply, and then drop back quickly as consequence of households deleveraging. Bank equity is depleted by more than $50 \%$ relative to its baseline level following these losses (bottom middle). The banking sector shrinks, reducing both assets (top right) and liabilities (bottom left) sharply as a result. The recovery of bank equity takes substantially longer than the mean-reversion of the shocks due to equity issuance costs. The net dividend paid by banks (bottom right) remains low for more than 15 years following the initial shock during a housing recession, reflecting the slow build-up in equity. The dynamics of the banking sector are in stark contrast to regular recessions, during which bank equity and dividends increase, and the banking sector expands slightly. 


\subsection{Bank equity, leverage, and housing booms}

The results of the previous section suggest that the interaction between household leverage and constrained credit supply from intermediaries is a powerful amplification mechanism in housing recessions.

Role of bank equity. To further isolate the effect of bank equity capital as state variable on equilibrium dynamics, we analyze the effect of an unanticipated reduction in internal bank equity, similar in magnitude to the losses banks suffer in a housing recession.

Figure 4: Effect of reduction in bank equity
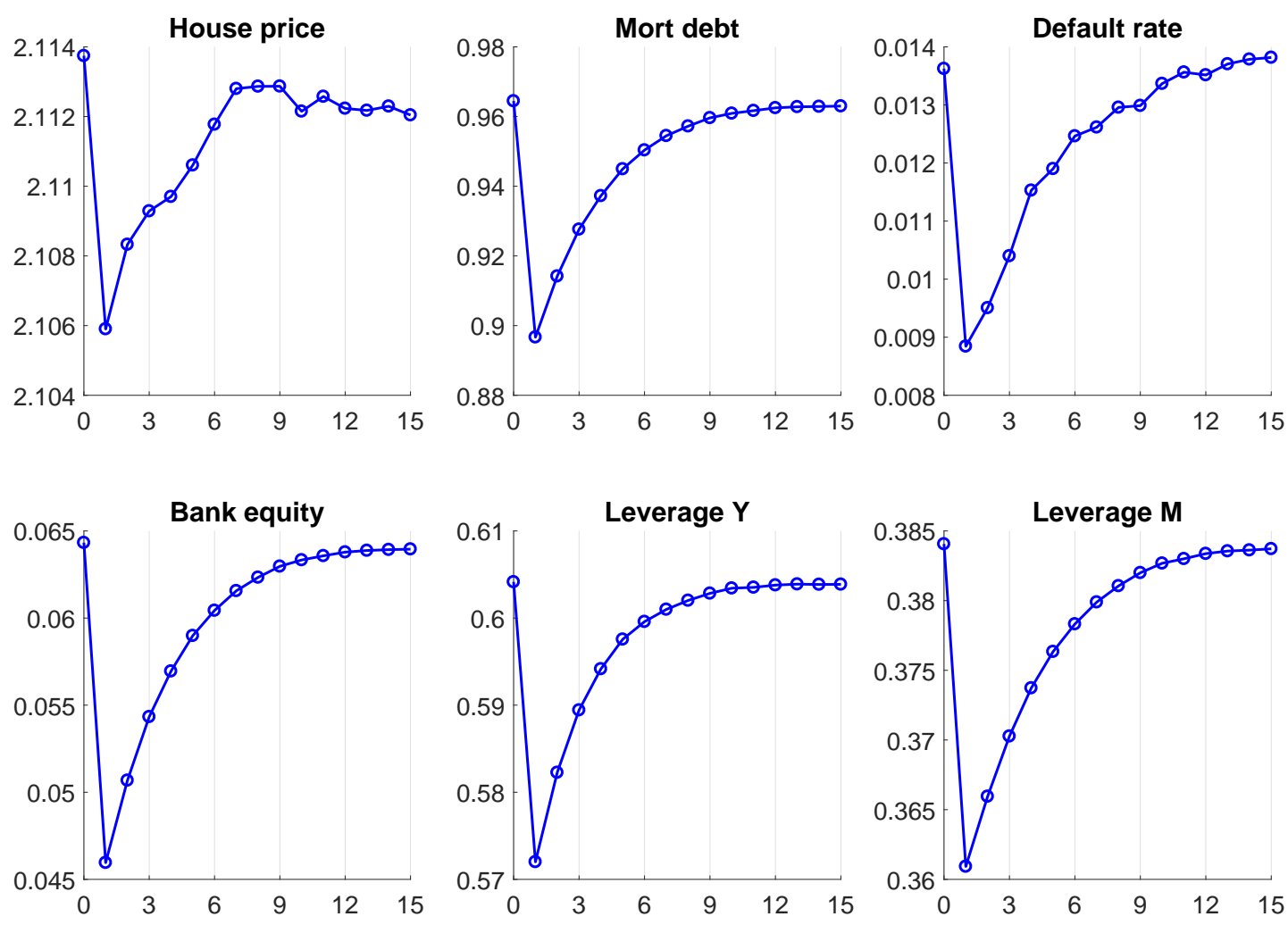

The generalized IRF plots are created by simulating the economy 10,000 times for 15 years, and plotting the average path of variables. The simulations are initialized at the ergodic distribution of the exogenous and endogenous states. The plots report the evolution of variables in levels.

Figure 4 illustrates the pure effect of a loss in bank equity. In the initial period, there is an unanticipated drop in bank equity by approximately $30 \%$ (bottom left), a somewhat smaller drop than what banks experience in housing recessions. Having less equity to back deposits, banks need to raise mortgage rates, and households need to cut back on borrowing. Total mortgage debt declines by roughly $1 / 3$ of the decline in housin reces- 
sions. House prices also fall, albeit by a much smaller magnitude than during housing recessions. As house prices drop by less, there is only a smaller wealth effect for young households, and less reallocation of housing capital from young to middle-aged, which in turn is consistent with the smaller drop in house prices.

Overall, figure 4 shows that the bank balance sheet effect has quantitatively large effects on credit supply and household leverage. It also clarifies that the deep fall in house prices during housing recessions (figure 2) is mainly caused by the combination of low income and high housing risk shocks. These shocks jointly diminish the viability of mortgage borrowing for young households, forcing them to shed housing capital to the middle-aged, who in turn have a lower marginal valuation of housing. ${ }^{10}$

Increased demand for safe assets. To which extent can greater demand for intermediation services in our model explain a boom in housing and mortgage debt? To answer this question, we simulate the economy for a specific sequence of shocks. The simulation starts at the ergodic distribution of all state variables. Then the economy experiences two unanticipated shocks: (i) an increased demand for safe assets, implemented as a higher marginal valuation of deposits $\left(\psi^{Y}, \psi^{M}\right)$, and (ii) a lower transition probability to a high housing risk state. After these shocks, the economy experiences average endowment income and the low-risk housing state for 6 consecutive years (a highly likely sequence of shock realizations to occur). In year 7, the exogenous state switches to low endowment and high housing risk, i.e., a housing recession. After that, the simulation progresses stochastically for 8 more years as the economy recovers.

Figure 5 shows the response of the economy to this sequence of shocks. The blue line considers only an increase in utility from deposits, calibrated such that the riskfree rate drops to zero. ${ }^{11}$ The red line considers in addition a reduction in the probability of transitioning to the high housing risk state by $3 \%$ (from .05 to .02). Both shocks have a strong positive effect on house prices and mortgage debt, triggering a credit-fueled housing boom. House prices rise by $17 \%$ and mortgage debt almost by $30 \%$ in the simulation with both shocks. As banks expand lending, they need to build up equity to satisfy their

\footnotetext{
${ }^{10}$ Interestingly, it is the combination of both shocks that causes large housing recessions in the model. A pure housing risk (i.e. second moment) shock, has effects similar to the unanticipated reduction in bank equity in figure 4. As discussed above, a pure endowment shock does not lead to a contraction of the banking sector.

${ }^{11}$ We calibrate the shock to deposit demand $\left(\psi^{Y}, \psi^{M}\right)$ such that riskfree rate without liquidity premium drops to zero as households supply a greater amount of deposits to banks. This implies that the deposit rate, which is the riskfree rate minus the liquidity premium, drops to $-3 \%$ in the initial period of the simulation. We feed in this large shock as a stand-in for other types shifts to safe asset demand, such as population aging.
} 
Figure 5: Housing boom and bust
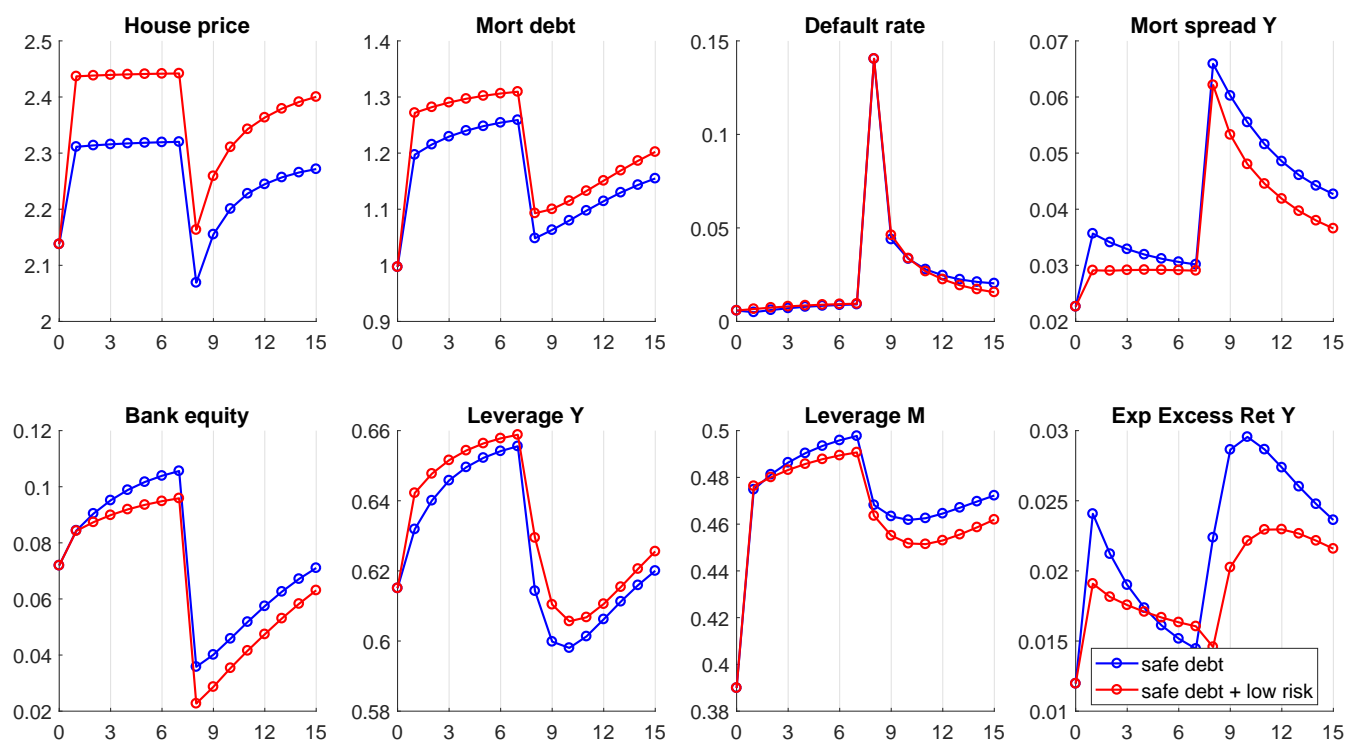

The generalized IRF plots are created by simulating the economy 10,000 times for 15 years, and plotting the average path of variables. The simulations are initialized at the ergodic distribution of the exogenous and endogenous states. All simulations have the same sequence of shocks for the first seven years, which are six years of average endowment and low housing risk realizations, followed by a housing recession (low endowment, high housing risk) in year seven. The plots report the evolution of variables in levels.

solvency constraint; however, perception of lower risk (red vs. blue line) causes them to build up a smaller equity buffer. The combination of both shocks leads to an endogenous relaxation of leverage constraints on households, causing a significant build-up of risk in the system. When the housing risk shock hits in year 7 , the mortgage default rate spikes at $15 \%$, almost doubling compared to a "standard" housing recession in the IRF plots of figure 3. House prices and mortgage debt almost completely fall back to the pre-boom levels during the ensuing crisis. Bank equity plummets, and both types of households aggressively delever. Young borrower leverage drops below its pre-boom level, while middle-aged leverage stays elevated.

Figure 6 shows that both the boom and the bust cause a reallocation of housing capital and wealth from young to middle-aged households. Even though young households increase leverage and housing wealth during the boom, they reduce their consumption of housing due to the strong rise in housing prices. The middle-aged profit most from the rise in all asset values as they hold most the economy's wealth. Consequently, they increase consumption of both housing and non-durables. Interestingly, the bust leads to a further reallocation of housing from the constrained young to the wealthy middleaged. The two bottom right panels illustrate the effect on mortgage spreads: despite the 
Figure 6: Housing boom and bust
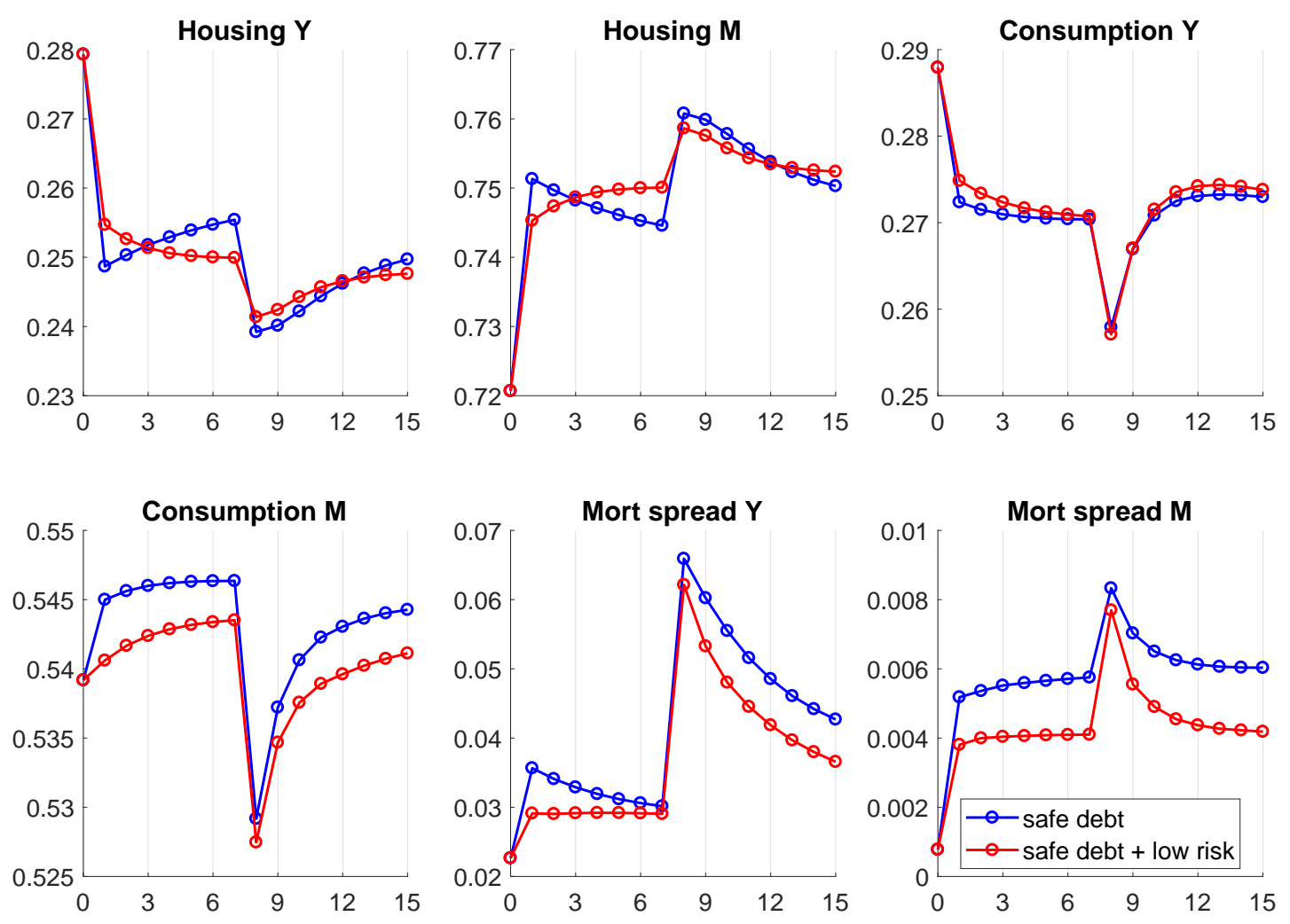

The generalized IRF plots are created by simulating the economy 10,000 times for 15 years, and plotting the average path of variables. The simulations are initialized at the ergodic distribution of the exogenous and endogenous states. All simulations have the same sequence of shocks for the first seven years, which are six years of average endowment and low housing risk realizations, followed by a housing recession (low endowment, high housing risk) in year seven. The plots report the evolution of variables in levels.

large rise in default risk of young households during the boom period, mortgage spreads only rise very little when both shocks are considered (red line). This is consistent with the view that mortgage spreads during the housing boom only imperfectly incorporated the increased riskiness of mortgages, as for example argued in Justiniano, Primiceri, and Tambalotti (2017).

\section{Conclusion}

The key feature of our model is that the supply of credit to borrowing constrained households depends on the risk taking capacity of financial intermediaries. As a result, when financial intermediaries are distressed, constrained households endogenously choose to reduce their mortgage leverage and must cut back on their consumption. This connection 
between the health of the financial sector and real economy gives us a novel propogation mechanism for shocks to the financial system.

In our first quantitative counterfactual, we find that an increase in mortgage defaults inhibits the ability of intermediaries to create safe assets and thereby leads to a low interest rate. In addition, the depletion of intermediary equity due to these losses lead to deleveraging and a reduction in consumption by the most constrained households, as well as a drop in house prices due to their reduced collateral value. We also find in a second similar exercise that an exogenous reduction in the equity capital of intermediary leads to an increase in mortgage spreads, a decrease in mortgage leverage, a decrease in the consumption of the most constrained households, and a reduction in house prices. Finally, we use our model to show that a growing demand for safe assets leads to many features of the housing and credit boom of the 2000s and increases the severity of future financial crises after a shock to mortgage default. In particular we find that an increase in the demand for safe assets induces intermediaries to expand their balance sheet and make riskier loans, which induces households to borrow more and boosts the consumption of constrained households. However, after an increase in mortgage defaults, this increased size and riskiness of the financial sector leads to a more severe drop in household leverage, consumption of constrained households, and house prices.

Broadly speaking, our model implies that shocks to intermediary capital emphasized by the intermediary asset pricing literature building on He and Krishnamurthy (2013) cause a negative credit supply shock that induces households to delever and consume less as emphasized by the literature following Mian and Sufi (2011). Our model therefore has a novel transmission mechanism of distress from Wall Street to Main Street, because leverage is endogenously determined. Going forward, we hope to enrich the general equilibrium effects of this transmission mechanism by making several features of our model endogenous. First, the fact that we have an endowment economy does not let us consider effects on output. Second, adding nominal rigidities would allow us to study additional mechanisms by which aggregate demand can affect output, which may feed back onto the health of the financial sector. Third, our current model of mortgage borrowing misses the fact that mortgages are long term and can only be refinanced when homeowners have sufficient home equity. Finally, liquidity constraints both for households and financial intermediaries can allow us to study aspects of the crisis ranging from banking panics to liquidity driven defaults on mortgages. 


\section{References}

Adelino, M., A. SchoAR, And F. SEVERino (2016): “Loan Originations and Defaults in the Mortgage Crisis: The Role of the Middle Class," Review of Financial Studies, 29(7), 1635-1670.

Adrian, T., E. Etula, AND T. Muir (2014): “Financial Intermediaries and the CrossSection of Asset Returns," Journal of Finance, 69(6), 2557-2596.

BARON, M. (2018): “Countercyclical Bank Equity Issuance," working paper.

Benmelech, E., R. Meisenzahl, And R. RAmCHARAN (2014): “The Real Effects of Liquidity During the Financial Crisis: Evidence from Automobiles," Quarterly Journal of Economics, 132(1), 317-365.

Bernanke, B. (2005): “The Global Saving Glut and the U.S. Current Account Deficit," Sandridge Lecture, Virginia Association of Economics, Richmond, VA.

Brunnermeier, M., And Y. SAnnikov (2014): “A Macroeconomic Model with a Financial Sector," American Economic Review, 104(2), 379-421.

Caballero, R., And E. FARHi (2018): “The Safety Trap," Review of Economic Studies, 85(1), 223-274.

Caballero, R., and A. Krishnamurthy (2009): “Global Imbalances and Financial Fragility," American Economic Review Papers and Proceedings, 99(2), 584-88.

CHOdorow-REICH, G. (2014): “The Employment Effects of Credit Market Disruptions: Firm-level Evidence from the 2008-09 Financial Crisis," Quarterly Journal of Economics, 129(1), 1-59.

Chodorow-Reich, G., And A. Falato (2018): “The Loan Covenant Channel: How Bank Health Transmits to the Real Economy," working paper.

Constantinides, G., And D. Duffie (1996): “Asset Pricing with Heterogeneous Consumers," Journal of Political Economy, 104(2), 219-240.

CorbaE, D., And E. Quintin (2015): “Leverage and the Foreclosure Crisis," Journal of Political Economy, 123, 1-65.

Di Maggio, M., And A. Kermani (2017): "Credit Induced Boom and Bust," Review of Financial Studies, 30(11), 3711-3758. 
Di Maggio, M., A. Kermani, B. Keys, T. Piskorski, R. Ramcharan, A. Seru, and V. YAO (2017): “Interest Rate Pass-Through: Mortgage Rates, Household Consumption and Voluntary Deleveraging," American Economic Review, 107(11), 3550-3588.

DiAMOND, W. (2018): "Safety Transformation and the Structure of the Financial System," working paper.

EleneV, V. (2018): “Mortgage Credit, Aggregate Demand, and Unconventional Monetary Policy," working paper.

EleneV, V., T. Landvoigt, and S. Van Nieuwerburgh (2018): “A Macroeconomic Model with Financially Constrained Producers and Intermediaries," working paper.

FaVAra, G., AND J. Imbs (2015): "Credit Supply and the Price of Housing," American Economic Review, 105(3), 958-92.

Favilukis, J., S. C. Ludvigson, And S. VAN Nieuwerburgh (2017): “The Macroeconomic Effects of Housing Wealth, Housing Finance, and Limited Risk Sharing in General Equilibrium," Journal of Political Economy, 125(1), 140-223.

Foote, C., L. Lowenstein, And P. Willen (2016): “Cross-Sectional Patterns of Mortgage Debt during the Housing Boom: Evidence and Implications," working paper.

Gabaix, X., A. Krishnamurthy, And O. Vigeron (2007): “Limits of Arbitrage: Theory and Evidence from the Mortgage-Backed Securities Market," Journal of Finance, 62(2), 557-595.

GeanaKoplos, J. (2010): “The Leverage Cycle," NBER Macroeconomics Annual 2009, 24, $1-65$.

Greenwald, D. (2018): “The Mortgage Credit Channel of Macroeconomic Transmission," working paper.

Greenwald, D., T. Landvoigt, and S. Van Nieuwerburgh (2018): “Financial Fragility with SAM?," working paper.

Guerrieri, V., And G. Lorenzoni (2017): “Credit Crises, Precautionary Savings and the Liquidity Trap," Quarterly Journal of Economics, 132(3), 1427-1467.

Guren, A., A. Krishnamurthy, and T. McQuade (2018): “Mortgage Design in an Equilibrium Model of the Housing Market," working paper. 
HAdDAD, V., AND T. Muir (2018): “Do Intermediaries Matter for Aggregate Asset Prices?," working paper.

HANSON, S. (2014): “Mortgage Convexity,” Journal of Financial Economics, 113(2), 270-299.

He, Z., B. Kelly, and A. Manela (2017): “Intermediary Asset Pricing: New Evidence from Many Asset Classes," Journal of Financial Economics, 126(1), 1-35.

He, Z., And A. KRishnamurthy (2013): “Intermediary Asset Pricing," American Economic Review, 103(2), 732-770.

Hedlund, A., And C. Garriga (2018): “Mortgage Debt, Consumption, and Illiquid Housing Markets in the Great Recession ," working paper.

IACOVIELlO, M. (2005): “House prices, borrowing constraints, and monetary policy in the business cycle," American Economic Review, 95(3), 739-764.

JordÀ, O., M. Schularick, AND A. TAYlOR (2015): “Betting the House," Economic Policy, 96(S1), S2-S18.

- (2016): “The Great Mortgaging: Housing Finance, Crises and Business Cycles," Economic Policy, 31(85), 107-152.

Justiniano, A., G. Primiceri, and A. Tambalotti (2017): “The Mortgage Rate Conundrum," Working Paper.

_ (forthcoming): "Credit Supply and the Housing Boom," Journal of Political Economy.

Kaplan, G., K. Mitman, and G. Violante (2017): “The Housing Boom and Bust: Model Meets Evidence," working paper.

Kaplan, G., And G. Violante (2014): “A Model of the Consumption Response to Fiscal Stimulus Payments," Econometrica, 82(4), 1199-1239.

KiYOtAKi, N., A. Michaelides, AND K. NikOlov (2011): “Winners and Losers in Housing Markets," Journal of Money, Credit and Banking, 43(2-3), 255-296.

KRIShNAmurthy, A., AND A. Vissing-Jorgensen (2012): “The Aggregate Demand for Treasury Debt," Journal of Political Economy, 120(2), 233-267.

LANDVOigt, T. (2016): “Financial Intermediation, Credit Risk, and Credit Supply During the Housing Boom," working paper. 
Landvoigt, T., M. Piazzesi, And M. Schneider (2015): “The Housing Market(s) of San Diego," American Economic Review, 105(4), 1371-1407.

Mian, A., K. RAO, And A. SUfi (2013): "Household Balance Sheets, Consumption, and the Economic Slump," Quarterly Journal of Economics, 128(4), 1687-1726.

MiAn, A., AND A. Sufi (2011): "House Prices, Home Equity-Based Borrowing, and the US Household Leverage Crisis," American Economic Review, 101(5), 2132-2156.

Ramcharan, R., S. Verani, and S. Van Den Heuvel (2016): "From Wall Street to Main Street: The Impact of the Financial Crisis on Consumer Credit Supply," Journal of Finance, 71(3), 1323-1356.

RouwenHORST, K. G. (1995): “Asset Pricing Implications of Equilibrium Business Cycle Models," Frontiers of Business Cycle Research, Princeton: Princeton University Press, pp. 294-330.

SChularick, M., AND A. TAYlor (2012): “Credit Booms Gone Bust: Monetary Policy, Leverage Cycles, and Financial Crises, 1870-2008," American Economic Review, 102(2), 1029-61.

SimseK, A. (2013): “Belief Disagreements and Collateral Constraints," Econometrica, 81(1), $1-53$.

WONG, A. (2018): "Population Aging and the Transmission of Monetary Policy to Consumption," working paper.

YaO, R., And H. Zhang (2005): "Optimal Consumption and Portfolio Choices with Risky Housing and Borrowing Constraints," Review of Financial Studies, 18(1), 197-239. 


\section{A Model}

\section{A.1 Proofs}

\section{A.1.1 Proposition 1}

In order to use variables that are stationary if the economy grows at a trend rate g, we renormalize the choices $\left(c_{t}^{M}, s_{t}^{M}, d_{t}^{M}, m_{t}^{M}\right)$ as well as prices $\left(P_{t}, p_{t}^{I}\right)$, and the bank dividend $x_{t}^{I}$. The rent $\rho_{t}^{M}$, interest rate $r_{t}$, and housing and equity shares $\left(h_{t}^{M}, b_{t}^{M}\right)$ are stationary variables along such a balanced growth path. This gives first order conditions that are more conveniant for computation, and the validity of our proof does not require us to assume such a stationary equilibrium exists.

Thus the full problem of the middle-aged along a balanced growth path (i.e., detrended by $\left.\bar{Y}_{t}\right)$ is

$$
\begin{aligned}
V^{M}\left(w_{t}^{M}, \mathcal{Z}_{t}\right)= & \max _{c_{t}^{M}, s_{t}^{M}, \alpha_{t}^{M}} \frac{\left(\left(c_{t}^{M}\right)^{1-\theta}\left(s_{t}^{M}\right)^{\theta}\right)^{1-\gamma}}{1-\gamma}+\psi \frac{\left(d_{t}^{M}\right)^{1-\gamma}}{1-\gamma} \\
& +\beta\left(1-\pi^{M}\right) \mathrm{E}_{t}\left[G^{1-\gamma} \max \left\{V^{M}\left(w_{t+1}^{M, n d}, \mathcal{Z}_{t+1}\right), V^{M}\left(w_{t+1}^{M, d}, \mathcal{Z}_{t+1}\right)\right\}\right] \\
& +\beta \pi^{M} \mathrm{E}_{t}\left[G^{1-\gamma} \max \left\{u^{O}\left(w_{t+1}^{M, n d}, \mathcal{Z}_{t+1}\right), u^{O}\left(w_{t+1}^{M, d}, \mathcal{Z}_{t+1}\right)\right\}\right],
\end{aligned}
$$

subject to the budget constraint

$$
w_{t}^{M}=c_{t}^{M}+\rho_{t}^{M} \mathcal{S}_{t}^{M}+h_{t}^{M}\left(P_{t}-\rho_{t}^{M}\right)+p_{t}^{I} b_{t}^{M}+\frac{d_{t}^{M}}{1+r_{t}}-q^{M}\left(\alpha_{t}^{M}\right) m_{t}^{M},
$$

and the definition of next-period wealth for non-defaulters

$$
w_{t+1}^{M, n d}=\left(1-\delta_{H}\right) P_{t+1} \epsilon_{t+1}^{M} h_{t}^{M}+\frac{d_{t}^{M}}{G}+b_{t}^{M}\left(p_{t+1}^{I}+x_{t+1}\right)-\frac{m_{t}^{M}}{G},
$$

and for defaulters

$$
w_{t+1}^{M, d}=\left(1-\lambda^{M}\right)\left(\frac{d_{t}^{M}}{G}+b_{t}^{M}\left(p_{t+1}^{I}+x_{t+1}\right)\right),
$$

where we have defined the growth factor $G=\exp (g)$.

Denote the savings of a middle-aged household by

$$
S_{t}^{M}=h_{t}^{M}\left(P_{t}-\rho_{t}^{M}\right)+p_{t}^{I} b_{t}^{M}+\frac{d_{t}^{M}}{1+r_{t}}-q^{M}\left(\alpha_{t}^{M}\right) m_{t}^{M}
$$


Further define the portfolio return conditional on defaulting and not defaulting, respectively, as

$$
R_{t+1}^{M, j}=G \frac{w_{t+1}^{M, j}}{S_{t}^{M}}, j=d, n d,
$$

where

$$
\begin{aligned}
R_{t+1}^{M, n d} & =G\left(1-\delta_{H}\right) P_{t+1} \epsilon_{t+1}^{M} \hat{h}_{t}^{M}-\hat{m}_{t}^{M}+\hat{d}_{t}^{M}+G\left(p_{t+1}^{I}+x_{t+1}^{I}\right) \hat{b}_{t}^{M} \\
R_{t+1}^{M, d} & =\hat{d}_{t}^{M}+G\left(p_{t+1}^{I}+x_{t+1}^{I}\right) \hat{b}_{t}^{M}
\end{aligned}
$$

and we have defined quantity portfolio shares $\hat{h}_{t}^{M}=h_{t}^{M} / S_{t}^{M}, \hat{b}_{t}^{M}=b_{t}^{M} / S_{t}^{M}, \hat{d}_{t}^{M}=$ $d_{t}^{M} / S_{t}^{M}$, and $\hat{m}_{t}^{M}=m_{t}^{M} / S_{t}^{M}$.

The usual results for Cobb-Douglas utility functions imply that the optimal expenditure on non-durable and housing services consumption are

$$
\begin{aligned}
& c_{t}^{M}=(1-\theta)\left(w_{t}^{M}-S_{t}^{M}\right), \\
& s_{t}^{M}=\frac{\theta}{\rho_{t}^{M}}\left(w_{t}^{M}-S_{t}^{M}\right) .
\end{aligned}
$$

We conjecture that the value function on the right hand side of equation 15 has the form

$$
V^{M}\left(w_{t}^{M}, \mathcal{Z}_{t}\right)=v^{M}\left(\mathcal{Z}_{t}\right) \frac{\left(w_{t}^{M}\right)^{1-\gamma}}{1-\gamma}
$$

as in (3), where $v^{M}\left(\mathcal{Z}_{t}\right)$ only depends on aggregate states exogenous to the individual household. We want to then show that the value function must also take this form on the left hand side of 15. That is, we show that the Bellman operator of the middle aged household's problem maps functions that are homogenous of degree $1-\gamma$ to functions that are homogenous of degree $1-\gamma$.

This allows us to rewrite the value function as

$$
V^{M}\left(w_{t}^{M}, \mathcal{Z}_{t}\right)=\max _{S_{t}^{M}} \frac{\Theta^{M}\left(\mathcal{Z}_{t}\right)}{1-\gamma}\left(w_{t}^{M}-S_{t}^{M}\right)^{1-\gamma}+\left(S_{t}^{M}\right)^{1-\gamma} A^{M}\left(\mathcal{Z}_{t}\right)
$$


where we defined the portfolio choice problem per dollar of savings

$$
\begin{aligned}
A^{M}\left(\mathcal{Z}_{t}\right)= & \max _{\hat{\alpha}_{t}^{M}} \psi \frac{\left(\hat{d}_{t}^{M}\right)^{1-\gamma}}{1-\gamma} \\
& +\beta \mathrm{E}_{t}\left[\max \left\{\frac{\left(R_{t+1}^{M, n d}\right)^{1-\gamma}}{1-\gamma}, \frac{\left(R_{t+1}^{M, d}\right)^{1-\gamma}}{1-\gamma}\right\}\left(\pi^{M} v^{O}\left(\mathcal{Z}_{t+1}\right)+\left(1-\pi^{M}\right) v^{M}\left(\mathcal{Z}_{t+1}\right)\right)\right]
\end{aligned}
$$

subject to the budget constraint

$$
1=\hat{h}_{t}^{M}\left(P_{t}-\rho_{t}^{M}\right)+p_{t}^{I} \hat{b}_{t}^{M}+\frac{\hat{d}_{t}^{M}}{1+r_{t}}-q^{M}\left(\hat{\alpha}_{t}^{M}\right) \hat{m}_{t}^{M}
$$

and where $\Theta^{M}\left(\mathcal{Z}_{t}\right)=\left((1-\theta)^{1-\theta}\left(\frac{\theta}{\rho_{t}^{M}}\right)^{\theta}\right)^{1-\gamma}$. The last term of the portfolio budget constraint (19) uses the property that the mortgage price $q^{M}\left(\hat{\alpha}_{t}^{M}\right)$ is homogeneous of degree zero, conditional on the conjectured value function.

Taking the first-order condition with respect to $S_{t}^{M}$ and solving, we get

$$
S_{t}^{M}=\underbrace{\frac{\left((1-\gamma) A^{M}\left(\mathcal{Z}_{t}\right)\right)^{1 / \gamma}}{\Theta^{M}\left(\mathcal{Z}_{t}\right)^{1 / \gamma}+\left((1-\gamma) A^{M}\left(\mathcal{Z}_{t}\right)\right)^{1 / \gamma}}}_{=B^{M}\left(\mathcal{Z}_{t}\right)} w_{t}^{M} .
$$

Equation (20) implies that all middle-aged households save the same fraction of their wealth, with this fraction given by $B^{M}\left(\mathcal{Z}_{t}\right)$.

Reinserting this solution for $S_{t}^{M}$ into the value function gives

$$
V^{M}\left(w_{t}^{M}, \mathcal{Z}_{t}\right)=\frac{\left(w_{t}^{M}\right)^{1-\gamma}}{1-\gamma}\left[\Theta^{M}\left(\mathcal{Z}_{t}\right)\left(1-B^{M}\left(\mathcal{Z}_{t}\right)\right)^{1-\gamma}+(1-\gamma) A^{M}\left(\mathcal{Z}_{t}\right) B^{M}\left(\mathcal{Z}_{t}\right)^{1-\gamma}\right] .
$$

This confirms the conjecture from (3) with

$$
v^{M}\left(\mathcal{Z}_{t}\right)=\Theta^{M}\left(\mathcal{Z}_{t}\right)\left(1-B^{M}\left(\mathcal{Z}_{t}\right)\right)^{1-\gamma}+(1-\gamma) A^{M}\left(\mathcal{Z}_{t}\right) B^{M}\left(\mathcal{Z}_{t}\right)^{1-\gamma}
$$

Note that equation (21) is a recursion in $v^{M}\left(\mathcal{Z}_{t}\right)$, since $A^{M}\left(\mathcal{Z}_{t}\right)$ depends on the expectation of $v^{M}\left(\mathcal{Z}_{t+1}\right)$.

Since the optimization problem in (18) is independent of individual wealth, all middleaged households choose the same portfolio and savings shares, irrespective of their level 
of wealth.

\section{A.1.2 Proposition 2}

As for the middle-aged, choices $\left(c_{t}^{Y}, s_{t}^{Y}, m_{t}^{Y}, d_{t}^{Y}\right)$ grow at the trend rate $g$. Shares $\eta_{t}^{Y}$ of the endowment income are stationary.

Thus the detrended problem along the BGP of a household in the young generation is

$$
\begin{aligned}
V^{Y}\left(w_{t}^{Y}, \mathcal{Z}_{t}\right)= & \max _{c_{t}^{Y}, s_{t}^{Y}, h_{t}^{Y}, m_{t}^{Y}, d_{t}^{Y}, \eta_{t}^{Y}} \frac{\left(\left(c_{t}^{Y}\right)^{1-\theta}\left(s_{t}^{Y}\right)^{\theta}\right)^{1-\gamma}}{1-\gamma}+\psi \frac{\left(d_{t}^{Y}\right)^{1-\gamma}}{1-\gamma} \\
& +\beta\left(1-\pi^{Y}\right) \mathrm{E}_{t}\left[G^{1-\gamma} \max \left\{V^{Y}\left(w_{t+1}^{Y Y, d}, \mathcal{Z}_{t+1}\right), V^{Y}\left(w_{t+1}^{Y Y, n d}, \mathcal{Z}_{t+1}\right)\right\}\right] \\
& +\beta \pi^{Y} \mathrm{E}_{t}\left[G^{1-\gamma} \max \left\{V^{M}\left(w_{t+1}^{Y M, d}, \mathcal{Z}_{t+1}\right), V^{M}\left(w_{t+1}^{Y M, n d}, \mathcal{Z}_{t+1}\right)\right\}\right],
\end{aligned}
$$

subject to

$$
w_{t}^{Y}=c_{t}^{Y}+\rho_{t}^{Y} s_{t}^{Y}+\left(P_{t}-\rho_{t}^{Y}\right) h_{t}^{Y}-q^{Y}\left(\alpha_{t}^{Y}\right) m_{t}^{Y}+\frac{d_{t}^{Y}}{1+r_{t}},
$$

and where $\epsilon_{t+1}^{Y}$ is an idiosyncratic default penalty that is i.i.d. across households and time. Next-period wealth conditional on defaulting is

$$
\begin{aligned}
& w_{t+1}^{Y Y, d}=\frac{d_{t}^{Y}}{G}+\left(1-\lambda^{Y}\right)\left(v Y_{t+1}^{*}+p_{t+1}^{Y}\right) \eta_{t}^{Y} \\
& \left.w_{t+1}^{Y M, d}=\frac{d_{t}^{Y}}{G}+\left(1-\lambda^{Y}\right)(1-v) Y_{t+1}^{*}\right) \eta_{t}^{Y}
\end{aligned}
$$

Next-period wealth conditional on not defaulting is

$$
\begin{gathered}
w_{t+1}^{Y Y, n d}=\left(1-\delta_{H}\right) P_{t+1} \epsilon_{t+1}^{Y} h_{t}^{Y}-\frac{m_{t}^{Y}}{G}+\frac{d_{t}^{Y}}{G}+\left(v Y_{t+1}^{*}+p_{t+1}^{Y}\right) \eta_{t}^{Y}, \\
w_{t+1}^{Y M, n d}=\left(1-\delta_{H}\right) P_{t+1} \epsilon_{t+1}^{Y} h_{t}^{Y}-\frac{m_{t}^{Y}}{G}+\frac{d_{t}^{Y}}{G}+(1-v) Y_{t+1}^{*} \eta_{t}^{Y} .
\end{gathered}
$$

Denote the savings of a young household by

$$
S_{t}^{Y}=h_{t}^{Y}\left(P_{t}-\rho_{t}^{Y}\right)+\frac{d_{t}^{Y}}{1+r_{t}}+\eta_{t}^{Y} p_{t}^{Y}-q^{Y}\left(\alpha_{t}^{Y}\right) m_{t}^{Y} .
$$

Further define the portfolio return conditional on defaulting and not defaulting, respec- 
tively, as

$$
R_{t+1}^{Y k, j}=G \frac{w_{t+1}^{Y k, j}}{S_{t}^{Y}}
$$

for $j=d, n d$ and $k=Y, M$, where

$$
\begin{aligned}
R_{t+1}^{Y Y, n d} & =G\left(1-\delta_{H}\right) P_{t+1} \epsilon_{t+1}^{Y} \hat{h}_{t}^{Y}-\hat{m}_{t}^{Y}+\hat{d}_{t}^{M}+\left(v Y_{t+1}^{*}+p_{t+1}^{Y}\right) \hat{\eta}_{t}^{Y} \\
R_{t+1}^{Y Y, d} & =\hat{d}_{t}^{Y}+\left(1-\lambda^{Y}\right)\left(v Y_{t+1}^{*}+p_{t+1}^{Y}\right) \hat{\eta}_{t}^{Y} \\
R_{t+1}^{Y M, n d} & =G\left(1-\delta_{H}\right) P_{t+1} \epsilon_{t+1}^{Y} \hat{h}_{t}^{Y}-\hat{m}_{t}^{Y}+\hat{d}_{t}^{M}+(1-v) Y_{t+1}^{*} \hat{\eta}_{t}^{Y} \\
R_{t+1}^{Y M, d} & =\hat{d}_{t}^{Y}+\left(1-\lambda^{Y}\right)(1-v) Y_{t+1}^{*} \hat{\eta}_{t}^{Y},
\end{aligned}
$$

and we have defined quantity portfolio shares $\hat{h}_{t}^{Y}=h_{t}^{Y} / S_{t}^{Y}, \hat{d}_{t}^{Y}=d_{t}^{Y} / S_{t}^{Y}, \hat{m}_{t}^{Y}=m_{t}^{Y} / S_{t}^{Y}$, and $\hat{\eta}_{t}^{Y} / S_{t}^{Y}$.

The usual results for Cobb-Douglas utility functions imply that the optimal expenditure on non-durable and housing services consumption are

$$
\begin{aligned}
& c_{t}^{Y}=(1-\theta)\left(w_{t}^{Y}-S_{t}^{Y}\right), \\
& s_{t}^{Y}=\frac{\theta}{\rho_{t}^{Y}}\left(w_{t}^{Y}-S_{t}^{Y}\right) .
\end{aligned}
$$

We conjecture that the value function has the form

$$
V^{Y}\left(w_{t}^{Y}, \mathcal{Z}_{t}\right)=v^{Y}\left(\mathcal{Z}_{t}\right) \frac{\left(w_{t}^{Y}\right)^{1-\gamma}}{1-\gamma}
$$

as in (4), where $v^{Y}\left(\mathcal{Z}_{t}\right)$ only depends on aggregate states exogenous to the individual household.

This allows us to rewrite the value function as

$$
V^{M}\left(w_{t}^{Y}, \mathcal{Z}_{t}\right)=\max _{S_{t}^{Y}} \frac{\Theta^{Y}\left(\mathcal{Z}_{t}\right)}{1-\gamma}\left(w_{t}^{Y}-S_{t}^{Y}\right)^{1-\gamma}+\left(S_{t}^{Y}\right)^{1-\gamma} A^{Y}\left(\mathcal{Z}_{t}\right)
$$


where we defined the portfolio choice problem per dollar of savings

$$
\begin{aligned}
A^{Y}\left(\mathcal{Z}_{t}\right)= & \max _{\hat{\alpha}_{t}^{Y}} \psi \frac{\left(\hat{d}_{t}^{Y}\right)^{1-\gamma}}{1-\gamma} \\
& +\beta\left(1-\pi^{Y}\right) \mathrm{E}_{t}\left[\max \left\{\frac{\left(R_{t+1}^{Y Y, n d}\right)^{1-\gamma}}{1-\gamma}, \frac{\left(R_{t+1}^{Y Y, d}\right)^{1-\gamma}}{1-\gamma}\right\} v^{Y}\left(\mathcal{Z}_{t+1}\right)\right] \\
& +\beta \pi^{Y} \mathrm{E}_{t}\left[\max \left\{\frac{\left(R_{t+1}^{Y M, n d}\right)^{1-\gamma}}{1-\gamma}, \frac{\left(R_{t+1}^{Y M, d}\right)^{1-\gamma}}{1-\gamma}\right\} v^{M}\left(\mathcal{Z}_{t+1}\right)\right]
\end{aligned}
$$

subject to the budget constraint

$$
1=\hat{h}_{t}^{Y}\left(P_{t}-\rho_{t}^{Y}\right)+\frac{\hat{d}_{t}^{Y}}{1+r_{t}}+\hat{\eta}_{t}^{Y} p_{t}^{Y}-q^{Y}\left(\hat{\alpha}_{t}^{Y}\right) \hat{m}_{t}^{Y}
$$

and where $\Theta^{Y}\left(\mathcal{Z}_{t}\right)=\left((1-\theta)^{1-\theta}\left(\frac{\theta}{\rho_{t}^{Y}}\right)^{\theta}\right)^{1-\gamma}$. The last term of the portfolio budget constraint (25) uses the property that the mortgage price $q^{Y}\left(\alpha_{t}^{Y}\right)$ is homogeneous of degree zero in household wealth and savings, conditional on the conjectured value function, such that $q^{Y}\left(\hat{\alpha}_{t}^{Y}\right)=q^{Y}\left(\alpha_{t}^{Y}\right)$, see also proposition 4 .

Taking the first-order condition with respect to $S_{t}^{Y}$ and solving, we get

$$
S_{t}^{Y}=\underbrace{\frac{\left((1-\gamma) A^{Y}\left(\mathcal{Z}_{t}\right)\right)^{1 / \gamma}}{\Theta^{Y}\left(\mathcal{Z}_{t}\right)^{1 / \gamma}+\left((1-\gamma) A^{Y}\left(\mathcal{Z}_{t}\right)\right)^{1 / \gamma}}}_{=B^{Y}\left(\mathcal{Z}_{t}\right)} w_{t}^{Y} .
$$

Equation (26) implies that all young households save the same fraction of their wealth, with this fraction given by $B^{Y}\left(\mathcal{Z}_{t}\right)$.

Reinserting this solution for $S_{t}^{Y}$ into the value function gives

$$
V^{Y}\left(w_{t}^{Y}, \mathcal{Z}_{t}\right)=\frac{\left(w_{t}^{Y}\right)^{1-\gamma}}{1-\gamma}\left[\Theta^{Y}\left(\mathcal{Z}_{t}\right)\left(1-B^{Y}\left(\mathcal{Z}_{t}\right)\right)^{1-\gamma}+(1-\gamma) A^{Y}\left(\mathcal{Z}_{t}\right) B^{Y}\left(\mathcal{Z}_{t}\right)^{1-\gamma}\right] .
$$

This confirms the conjecture from (4) with

$$
v^{Y}\left(\mathcal{Z}_{t}\right)=\Theta^{Y}\left(\mathcal{Z}_{t}\right)\left(1-B^{Y}\left(\mathcal{Z}_{t}\right)\right)^{1-\gamma}+(1-\gamma) A^{Y}\left(\mathcal{Z}_{t}\right) B^{Y}\left(\mathcal{Z}_{t}\right)^{1-\gamma}
$$

Note that equation (27) is a recursion in $v^{Y}\left(\mathcal{Z}_{t}\right)$, since $A^{Y}\left(\mathcal{Z}_{t}\right)$ depends on the expectation of $v^{Y}\left(\mathcal{Z}_{t+1}\right)$. 
Since the optimization problem in (24) is independent of individual wealth, all young households choose the same portfolio and savings shares, irrespective of their level of wealth.

\section{A.1.3 Proposition 4}

Proposition 4 was proven in the main text taking as given the stochastic discount factor of the intermediary. In this proof, we derive the intermediary's stochastic discount factor from its optimization problem. As above, we normalize all variables to grow at a rate $G=\exp (g)$ each period so that the first order conditions we derive are consistent with a balanced growth path. The proof does not assume this balanced growth path exists, but this provides expressions useful for the numerical solution of the model. The detrended value function is

$$
V^{I}\left(e_{t}, \mathcal{Z}_{t}\right)=\max _{I_{t}, D_{t}, N_{t}^{Y}, N_{t}^{M}} \tau e_{t}-I_{t}-\frac{\chi}{2} I_{t}^{2}+\mathrm{E}_{t}\left[G M_{t+1}^{M} V^{I}\left(e_{t+1}, \mathcal{Z}_{t+1}\right)\right]
$$

subject to the budget constraint

$$
(1-\tau) e_{t}+I_{t}-C\left(I_{t}, \bar{Y}_{t}\right)+\frac{D_{t}}{1+r_{t}}=N_{t}^{Y} q^{Y}\left(\alpha_{t}^{Y}\right)+N_{t}^{M} q^{M}\left(\alpha_{t}^{M}\right),
$$

the transition law for equity

$$
e_{t+1}=\left(N_{t}^{Y} \mathcal{P}_{t+1}^{Y}+N_{t}^{M} \mathcal{P}_{t+1}^{M}-D_{t}\right) / G,
$$

and the regulatory capital constraint for the worst-payoff state next period

$$
D_{t} \leq\left(1-\bar{e}^{\Upsilon}\right) N_{t}^{Y} \mathcal{P}^{\gamma}\left(\underline{z}_{t}\right)+\left(1-\bar{e}^{M}\right) N_{t}^{M} \mathcal{P}^{M}\left(\underline{z}_{t}\right) .
$$

The regulatory capital constraint is effectively an endogenous leverage constraint.

The Lagrangian form of the problem, with Lagrange multiplier $\mu_{t}^{I^{*}}$ on the (occasionally binding) regulatory capital constraint and multiplier $\kappa_{t}^{I}$ on the intratemporal budget 
constraint, is

$$
\begin{array}{r}
\max _{I_{t}, D_{t}, N_{t}^{Y}, N_{t}^{M}} \tau e_{t}-I_{t}+\mathrm{E}_{t}\left[G M_{t+1}^{M} V^{I}\left(\left(N_{t}^{Y} \mathcal{P}_{t+1}^{Y}+N_{t}^{M} \mathcal{P}_{t+1}^{M}-D_{t}\right) / G, \mathcal{Z}_{t+1}\right)\right] \\
+\mu_{t}^{I^{*}}\left[D_{t}-\left(1-\bar{e}^{Y}\right) N_{t}^{Y} \mathcal{P}^{Y}\left(\underline{z}_{t}\right)-\left(1-\bar{e}^{M}\right) N_{t}^{M} \mathcal{P}^{M}\left(\underline{z}_{t}\right)\right] \\
+\kappa_{t}^{I}\left[(1-\tau) e_{t}+I_{t}-\frac{\chi}{2} I_{t}^{2}+\frac{D_{t}}{1+r_{t}}-\left(N_{t}^{Y} q^{Y}\left(\alpha_{t}^{Y}\right)+N_{t}^{M} q^{M}\left(\alpha_{t}^{M}\right)\right)\right] .
\end{array}
$$

Assets held by the intermediary have value for two reasons. First, their payoff in the worst aggregate state loosens the regulatory capital constraint of it is binding. Second, assets provide wealth in the future, which is valued by a stochastic discount factor determined by the intermediary's shadow value of equity. Taking the FOC for issuance $I_{t}$, the shadow value of internal funds is

$$
\kappa_{t}^{I}=\frac{1}{1-\chi I_{t}} .
$$

Hence, the marginal value of equity is

$$
\frac{\partial V^{I}\left(e_{t}, \mathcal{Z}_{t}\right)}{\partial e_{t}}=\tau+(1-\tau) \kappa_{t}^{I}=\tau+\frac{1-\tau}{1-\chi I_{t}} .
$$

We define the intermediary's shadow value SDF (which captures only this second source of value) as

$$
M_{t+1}^{I}=M_{t+1}^{M}\left(1-\chi I_{t}\right)\left(\tau+\frac{1-\tau}{1-\chi I_{t+1}}\right) .
$$

Letting $\mu_{t}^{I}=\mu_{t}^{I^{*}}\left(1-\chi I_{t}\right)$ be a renormalization of the Lagrange multiplier on the constraint (28), the FOCs for deposits and loans are

$$
\begin{aligned}
\frac{1}{1+r_{t}} & =\mu_{t}^{I}+\mathrm{E}_{t}\left[M_{t+1}^{I}\right] \\
q^{M}\left(\alpha_{t}^{Y}\right) & =\mu_{t}^{I} \mathcal{P}^{M}\left(\underline{z}_{t}\right)+\mathrm{E}_{t}\left[M_{t+1}^{I} \mathcal{P}_{t+1}^{M}\right], \\
q^{Y}\left(\alpha_{t}^{Y}\right) & =\mu_{t}^{I} \mathcal{P}^{Y}\left(\underline{z}_{t}\right)+\mathrm{E}_{t}\left[M_{t+1}^{I} \mathcal{P}_{t+1}^{Y}\right] .
\end{aligned}
$$

The first-order conditions (30) and (31) define the mortgage pricing functions faced by borrowers, $q^{j}\left(\alpha_{t}^{j}\right)$, which depend on mortgage payoffs $\mathcal{P}_{t+1}^{j}$. From the definitions of these payoffs in (8) and (9), it is clear that they depend on borrower choices through the inverse mortgage leverage ratio $P_{t+1} h_{t}^{j} / m_{t}^{j}$ and default thresholds, which depend on choices through ratios of non-default to default wealth $w_{t+1}^{j, n d} / w_{t+1}^{j, d}$. Then by propositions 1 and 2, these payoffs are homogeneous of degree zero in borrower wealth. Individual 
borrowers choose identical portfolio shares of wealth, thus keeping these ratios independent of wealth levels.

\section{A.2 Characterization of Portfolio Problems}

\section{A.2.1 Middle-aged}

First-order conditions. The structure of the portfolio choice problem in (18) clarifies that there is a single default threshold for middle-aged $\bar{\epsilon}_{t+1}^{M}$, i.e. it does not depend on whether the households stays middle-aged or turns old. Attaching the Lagrange multiplier $\hat{\mu}_{t}^{M}$ to the portfolio budget constraint (19), the first-order condition for the portfolio shares of deposits is

$$
\begin{gathered}
\hat{\mu}_{t}^{M}\left(\frac{1}{1+r_{t}}-\frac{\partial q^{M}\left(\hat{\alpha}_{t}^{M}\right)}{\partial \hat{d}_{t}^{M}} \hat{m}_{t}^{M}\right)=\psi\left(\hat{d}_{t}\right)^{-\gamma}+\beta \mathrm{E}_{t}\left[\left(\pi^{M} v_{v}^{O}\left(\mathcal{Z}_{t+1}\right)+\left(1-\pi^{M}\right) v^{M}\left(\mathcal{Z}_{t+1}\right)\right) \times\right. \\
\left.\left(\int_{\bar{\epsilon}_{t+1}^{M}}^{\infty}\left(R_{t+1}^{M, n d}(\epsilon)\right)^{-\gamma} d F_{\epsilon, t+1}^{M}(\epsilon)+F_{\epsilon, t+1}^{M}\left(\bar{\epsilon}_{t+1}^{M}\right)(1-\lambda)\left(R_{t+1}^{M, d}\right)^{-\gamma}\right)\right]
\end{gathered}
$$

and for bank equity it is

$$
\begin{aligned}
& \hat{\mu}_{t}^{M}\left(p_{t}^{I}-\frac{\partial q^{M}\left(\hat{\alpha}_{t}^{M}\right)}{\partial \hat{s}_{t}^{M}} \hat{m}_{t}^{M}\right)=\beta \mathrm{E}_{t}\left[\left(\pi^{M} v^{O}\left(\mathcal{Z}_{t+1}\right)+\left(1-\pi^{M}\right) v^{M}\left(\mathcal{Z}_{t+1}\right)\right) \times\right. \\
& \left.\left(p_{t+1}^{I}+x_{t+1}^{I}\right)\left(\int_{\bar{\epsilon}_{t+1}^{M}}^{\infty}\left(R_{t+1}^{M, n d}(\epsilon)\right)^{-\gamma} d F_{\epsilon, t+1}^{M}(\epsilon)+F_{\epsilon, t+1}^{M}\left(\bar{\epsilon}_{t+1}^{M}\right)(1-\lambda)\left(R_{t+1}^{M, d}\right)^{-\gamma}\right)\right] .
\end{aligned}
$$

Housing and mortgages only pay off in the non-default case. Further, the mortgage price $q^{M}\left(h_{t}^{M}, m_{t}^{M}\right)$ depends on both choices, and households internalize the effect of their choices on this price. Thus the first-order condition for mortgages is

$$
\begin{aligned}
& \hat{\mu}_{t}^{M}\left(\frac{\partial q^{M}\left(\hat{\alpha}_{t}^{M}\right)}{\partial \hat{m}_{t}^{M}} \hat{m}_{t}^{M}+q^{M}\left(\hat{\alpha}_{t}^{M}\right)\right)= \\
& \beta \mathrm{E}_{t}\left[\left(\pi^{M} v^{O}\left(\mathcal{Z}_{t+1}\right)+\left(1-\pi^{M}\right) v^{M}\left(\mathcal{Z}_{t+1}\right)\right) \int_{\bar{\epsilon}_{t+1}^{M}}^{\infty}\left(R_{t+1}^{M, n d}(\epsilon)\right)^{-\gamma} d F_{\epsilon, t+1}^{M}(\epsilon)\right],
\end{aligned}
$$


and for housing we get

$$
\begin{aligned}
& \hat{\mu}_{t}^{M}\left(P_{t}-\rho_{t}^{M}-\frac{\partial q^{M}\left(\hat{\alpha}_{t}^{M}\right)}{\partial \hat{h}_{t}^{M}} \hat{m}_{t}^{M}\right)= \\
& \beta \mathrm{E}_{t}\left[\left(\pi^{M} v^{O}\left(\mathcal{Z}_{t+1}\right)+\left(1-\pi^{M}\right) v^{M}\left(\mathcal{Z}_{t+1}\right)\right)\left(1-\delta_{H}\right) P_{t+1} \int_{\bar{\epsilon}_{t+1}^{M}}^{\infty}\left(R_{t+1}^{M, n d}(\epsilon)\right)^{-\gamma} d F_{\epsilon, t+1}^{M}(\epsilon)\right],
\end{aligned}
$$

SDF of representative household. Since the solution to the optimization problem of middle-aged households scales in wealth (see Proposition 1), we can construct the stochastic discount factor of a representative middle-aged household. To do so, first note that the growth of wealth of any middle-aged household, conditional on the default decision, is given by

$$
\frac{w_{t+1}^{M, j}}{w_{t}^{M}}=\frac{S_{t}^{M} R_{t+1}^{M, j}}{w_{t}^{M}}=\frac{B^{M}\left(\mathcal{Z}_{t}\right) R_{t+1}^{M, j} w_{t}^{M}}{w_{t}^{M}}=B^{M}\left(\mathcal{Z}_{t}\right) R_{t+1}^{M, j},
$$

for $j=n d, d$. Thus the SDF conditional on not defaulting is

$$
M_{t+1}^{M, n d}=\beta \frac{\left(B^{M}\left(\mathcal{Z}_{t}\right) R_{t+1}^{M, n d}\right)^{-\gamma}}{v^{M}\left(\mathcal{Z}_{t}\right)}\left(\pi^{M} v^{O}\left(\mathcal{Z}_{t+1}\right)+\left(1-\pi^{M}\right) v^{M}\left(\mathcal{Z}_{t+1}\right)\right),
$$

and the SDF of defaulters is

$$
M_{t+1}^{M, d}=\beta \frac{\left(B^{M}\left(\mathcal{Z}_{t}\right) R_{t+1}^{M, d}\right)^{-\gamma}}{v^{M}\left(\mathcal{Z}_{t}\right)}\left(\pi^{M} v^{O}\left(\mathcal{Z}_{t+1}\right)+\left(1-\pi^{M}\right) v^{M}\left(\mathcal{Z}_{t+1}\right)\right),
$$

The default threshold is

$$
\bar{\epsilon}_{t+1}^{M}=\left(m_{t}^{M}-\lambda\left(d_{t}^{M}+b_{t}^{M}\left(p_{t+1}^{I}+x_{t+1}\right)\right)\right) \frac{1}{\left(1-\delta_{H}\right) P_{t+1} h_{t}^{M}} .
$$

Then the SDF for discounting payoffs that do not depend on the default decision (deposits and bank equity) is

$$
M_{t+1}^{M}=\int_{\bar{\epsilon}_{t+1}^{M}}^{\infty} M_{t+1}^{M, n d}(\epsilon) d F_{\epsilon, t}^{M}(\epsilon)+F_{\epsilon, t}^{M}\left(\bar{\epsilon}_{t}^{M}\right)\left(1-\lambda^{M}\right) M_{t+1}^{M, d} .
$$

Excess return equations. We can use the definition of the SDF in (36) and (37) to write the first-order conditions (32) - (35) more compactly. First, we note that the multiplier $\hat{\mu}_{t}^{M}$ 
is the marginal value of wealth per dollar of savings, which using (3) and (20) implies

$$
\hat{\mu}_{t}^{M}=\left(\frac{1}{B^{M}\left(\mathcal{Z}_{t}\right)}\right)^{-\gamma} v^{M}\left(\mathcal{Z}_{t}\right) .
$$

Dividing both sides of the first-order conditions by this expression gives

$$
\begin{aligned}
& \frac{1}{1+r_{t}}-\hat{m}_{t}^{M} q_{d}^{M}\left(\hat{\alpha}_{t}^{M}\right)=\frac{\psi}{v^{M}\left(\mathcal{Z}_{t}\right)}\left(\hat{d}_{t} B^{M}\left(\mathcal{Z}_{t}\right)\right)^{-\gamma}+\beta \mathrm{E}_{t}\left[M_{t+1}^{M}\right] \\
& p_{t}^{I}-\hat{m}_{t}^{M} q_{b}^{M}\left(\hat{\alpha}_{t}^{M}\right)=\beta \mathrm{E}_{t}\left[M_{t+1}^{M}\left(p_{t+1}^{I}+x_{t+1}^{I}\right)\right] \\
& q^{M}\left(\hat{\alpha}_{t}^{M}\right)+\hat{m}_{t}^{M} q_{m}^{M}\left(\hat{\alpha}_{t}^{M}\right)=\beta \mathrm{E}_{t}\left[\int_{\bar{\epsilon}_{t+1}^{M}}^{\infty} M_{t+1}^{M, n d}(\epsilon) d F_{\epsilon, t}^{M}(\epsilon)\right] \\
& P_{t}-\rho_{t}^{M}-\hat{m}_{t}^{M} q_{h}^{M}\left(\hat{\alpha}_{t}^{M}\right)=\beta \mathrm{E}_{t}\left[\int_{\bar{\epsilon}_{t+1}^{M}}^{\infty} M_{t+1}^{M, n d}(\epsilon) d F_{\epsilon, t}^{M}(\epsilon)\left(1-\delta_{H}\right) P_{t+1}\right]
\end{aligned}
$$

Note that equations (38) - (41) only characterize the relative portfolio shares of assets that middle-aged household invest in. To fully characterize the complete savings and portfolio choice problem of the middle generation, we can reduce these equation to three excess return equations by first defining the effective returns to mortgage borrowing and housing

$$
R_{t+1, m}^{M}=\frac{1}{q^{M}\left(\hat{\alpha}_{t}^{M}\right)+\hat{m}_{t}^{M} q_{m}^{M}\left(\hat{\alpha}_{t}^{M}\right)},
$$

and

$$
R_{t+1, h}^{M}=G \frac{\left(1-\delta_{H}\right) P_{t+1}}{P_{t}-\rho_{t}^{M}-\hat{m}_{t}^{M} q_{h}^{M}\left(\hat{\alpha}_{t}^{M}\right)^{\prime}},
$$

and the return to bank equity

$$
R_{t+1, e}^{M}=G \frac{p_{t+1}^{I}+x_{t+1}^{I}}{p_{t}^{I}-\hat{m}_{t}^{M} q_{b}^{M}\left(\hat{\alpha}_{t}^{M}\right)},
$$

and deposits

$$
R_{t+1, d}^{M}=\frac{1+r_{t}}{1-\left(1+r_{t}\right) \hat{m}_{t}^{M} q_{d}^{M}\left(\hat{\alpha}_{t}^{M}\right)} .
$$


Then the excess return restrictions are

$$
\begin{aligned}
& 0=\frac{\psi}{v^{M}\left(\mathcal{Z}_{t}\right)}\left(\hat{d}_{t} B^{M}\left(\mathcal{Z}_{t}\right)\right)^{-\gamma} R_{t+1, d}^{M}+\mathrm{E}_{t}\left[M_{t+1}^{M}\left(R_{t+1, d}^{M}-R_{t+1, e}^{M}\right)\right] \\
& 0=\mathrm{E}_{t}\left[\int_{\bar{\epsilon}_{t+1}^{M}}^{\infty} M_{t+1}^{M, n d}(\epsilon) d F_{\epsilon, t}^{M}(\epsilon)\left(R_{t+1, m}^{M}-R_{t+1, h}^{M}\right)\right] \\
& 0=\mathrm{E}_{t}\left[\int_{\bar{\epsilon}_{t+1}^{M}}^{\infty} M_{t+1}^{M, n d}(\epsilon) d F_{\epsilon, t}^{M}(\epsilon) R_{t+1, h}^{M}-M_{t+1}^{M} R_{t+1, e}^{M}\right] .
\end{aligned}
$$

Jointly with the optimal savings choice (20) and the recursive definition of the value function (21), these equations fully characterize the dynamic problem of the middlegeneration.

Mortgage pricing function derivatives. To compute the effective returns on all assets, we need to calculate the derivative of the mortgage pricing function $q^{M}\left(\hat{\alpha}_{t}^{M}\right)$ with respect to the elements of $\hat{\alpha}_{t}^{M}$. The first step is to differentiate the payoff function (8) with respect to these portfolio choices. We first define the home equity per dollar of mortgage debt of the marginal defaulter after bankruptcy losses

$$
\hat{\epsilon}_{t+1}^{M}=\frac{(1-\xi)\left(1-\delta_{H}\right) P_{t+1} h_{t}^{M} \bar{\epsilon}_{t+1}^{M}}{m_{t}^{M}}-1 .
$$

Then we get

$$
\begin{aligned}
\frac{\partial \mathcal{P}_{t+1}^{M}}{\partial m_{t}^{M}} & =\frac{f_{\epsilon, t}^{M}\left(\bar{\epsilon}_{t+1}^{M}\right) \hat{\epsilon}_{t+1}^{M}}{\left(1-\delta_{H}\right) P_{t+1} h_{t}^{M}}-F_{\epsilon, t}^{M}\left(\bar{\epsilon}_{t+1}^{M}\right)(1-\xi)\left(1-\delta_{H}\right) \frac{E_{t}\left(\epsilon^{M} \mid \epsilon^{M}<\bar{\epsilon}_{t+1}^{M}\right) P_{t+1} h_{t}^{M}}{\left(m_{t}^{M}\right)^{2}} \\
\frac{\partial \mathcal{P}_{t+1}^{M}}{\partial h_{t}^{M}} & =\left(1-\delta_{H}\right) P_{t+1}\left[\frac{1-\xi}{m_{t}^{M}} \int_{0}^{\bar{\epsilon}_{t+1}^{M}} \epsilon F_{\epsilon, t+1}(\epsilon)-f_{\epsilon, t+1}\left(\bar{\epsilon}_{t+1}^{M}\right) \frac{\hat{\epsilon}_{t+1}^{M}\left(\bar{\epsilon}_{t+1}^{M}\right)^{2}}{\left(1-\delta_{H}\right) P_{t+1} h_{t}^{M}}\right] \\
\frac{\partial \mathcal{P}_{t+1}^{M}}{\partial h_{t}^{M}} & =-f_{\epsilon, t+1}\left(\bar{\epsilon}_{t+1}^{M}\right) \frac{\hat{\epsilon}_{t+1}^{M} \lambda^{M}}{\left(1-\delta_{H}\right) P_{t+1} h_{t}^{M}} \\
\frac{\partial \mathcal{P}_{t+1}^{M}}{\partial b_{t}^{M}} & =-f_{\epsilon, t+1}\left(\bar{\epsilon}_{t+1}^{M}\right) \frac{\hat{\epsilon}_{t+1}^{M} \lambda^{M}\left(p_{t+1}^{I}+x_{t+1}\right)}{\left(1-\delta_{H}\right) P_{t+1} h_{t}^{M}}
\end{aligned}
$$

For any argument $\ell$ of the mortgage pricing function $q^{M}$ we have that

$$
\frac{\partial q^{M}\left(\alpha_{t}^{M}\right)}{\partial \ell}=\mu_{t}^{I} \frac{\partial \mathcal{P}^{M}\left(\underline{z}_{t}\right)}{\partial \ell}+\mathrm{E}_{t}\left[M_{t+1}^{I} \frac{\partial \mathcal{P}_{t+1}^{M}}{\partial \ell}\right] .
$$


Together with the first order conditions above, this characterizes the portfolio choice problem.

\section{A.2.2 Young}

SDF. We can construct the SDF of the young conditional on the default decision $j=n d, d$ and on the transition status $k=Y, M$ similar to the middle-aged as

$$
M_{t+1}^{Y k, j}=\beta \frac{\left(B^{Y}\left(\mathcal{Z}_{t}\right) R_{t+1}^{Y k, i}\right)^{-\gamma_{v} j}\left(\mathcal{Z}_{t+1}\right)}{v^{Y}\left(\mathcal{Z}_{t}\right)} .
$$

Hence the SDF for assets that only pay off in the non-default state, namely housing and mortgages, is

$$
M_{t+1}^{Y, n d}=\pi^{Y} \int_{\bar{\epsilon}_{t+1}^{Y, M}}^{\infty} M_{t+1}^{Y M, n d}(\epsilon) d F_{\epsilon, t+1}^{M}(\epsilon)+\left(1-\pi^{Y}\right) \int_{\bar{\epsilon}_{t+1}^{Y, Y}}^{\infty} M_{t+1}^{Y Y, n d}(\epsilon) F_{\epsilon, t+1}^{M}(\epsilon),
$$

and the SDF of defaulters is

$$
M_{t+1}^{Y, n d}=\pi^{Y}\left(1-\lambda^{Y}\right) F_{\epsilon, t+1}^{Y}\left(\bar{\epsilon}_{t+1}^{Y, M}\right) M_{t+1}^{Y M, d}+\left(1-\pi^{Y}\right)\left(1-\lambda^{Y}\right) F_{\epsilon, t+1}^{Y}\left(\bar{\epsilon}_{t+1}^{Y, Y}\right) M_{t+1}^{Y Y, d} .
$$

The SDF for discounting payoffs that do not depend on the default decision or the age transition (deposits) is

$$
M_{t+1}^{Y}=M_{t+1}^{Y, n d}+M_{t+1}^{Y, d} .
$$

We can also construct SDFs for discounting the endowment payoff that condition on the age transition status, but not on the default decision

$M_{t+1}^{Y k}=\left(1-\pi^{Y}\right)^{\mathbb{1}[k=Y]}\left(\pi^{Y}\right)^{\mathbb{1}[k=M]}\left[\int_{\bar{\epsilon}_{t+1}^{Y, k}}^{\infty} M_{t+1}^{Y k, n d}(\epsilon) d F_{\epsilon, t+1}^{k}(\epsilon)+\left(1-\lambda^{Y}\right) F_{\epsilon, t+1}^{Y}\left(\bar{\epsilon}_{t+1}^{Y, k}\right) M_{t+1}^{Y k, d}\right]$,

for $k=Y, M$. 
First-order conditions. The portfolio problem of the young is analogous to that of the middle-aged. Using the SDF definitions in (45) and (46), the first-order conditions are

$$
\begin{aligned}
& \frac{1}{1+r_{t}}-\hat{m}_{t}^{Y} q_{d}^{Y}\left(\hat{\alpha}_{t}^{Y}\right)=\frac{\psi}{v^{Y}\left(\mathcal{Z}_{t}\right)}\left(\hat{d}_{t}^{Y} B^{Y}\left(\mathcal{Z}_{t}\right)\right)^{-\gamma}+\beta \mathrm{E}_{t}\left[M_{t+1}^{Y}\right] \\
& q^{Y}\left(\hat{\alpha}_{t}^{Y}\right)+\hat{m}_{t}^{Y} q_{m}^{Y}\left(\hat{\alpha}_{t}^{Y}\right)=\beta \mathrm{E}_{t}\left[M_{t+1}^{Y, n d}\right] \\
& P_{t}-\rho_{t}^{Y}-\hat{m}_{t}^{Y} q_{h}^{Y}\left(\hat{\alpha}_{t}^{Y}\right)=\beta \mathrm{E}_{t}\left[M_{t+1}^{Y, n d}\left(1-\delta_{H}\right) P_{t+1}\right] \\
& p_{t}^{Y}-\hat{m}_{t}^{Y} q_{\eta}^{Y}\left(\hat{\alpha}_{t}^{Y}\right)=\beta \mathrm{E}_{t}\left[M_{t+1}^{Y Y}\left(\nu Y_{t+1}+p_{t+1}^{Y}\right)+M_{t+1}^{Y M}\left((1-v) Y_{t+1}+B_{t+1}^{O}\right)\right]
\end{aligned}
$$

Again as for the middle-aged we can reduce the system of Euler equations (48) - (51) to three excess return restrictions

$$
\begin{aligned}
0 & =\frac{\psi}{v^{Y}\left(\mathcal{Z}_{t}\right)}\left(\hat{d}_{t}^{Y} B^{Y}\left(\mathcal{Z}_{t}\right)\right)^{-\gamma} R_{t+1, d}^{Y}+\beta \mathrm{E}_{t}\left[M_{t+1}^{Y} R_{t+1, d}^{Y}-M_{t+1}^{Y, n d} R_{t+1, m}^{Y}\right] \\
0 & =\beta \mathrm{E}_{t}\left[M_{t+1}^{Y, n d}\left(R_{t+1, m}^{M}-R_{t+1, h}^{M}\right)\right] \\
0 & =\beta \mathrm{E}_{t}\left[M_{t+1}^{Y, n d} R_{t+1, h}^{M}-M_{t+1}^{Y Y} R_{t+1, \eta}^{Y Y}-M_{t+1}^{Y M} R_{t+1, \eta}^{Y M}\right]
\end{aligned}
$$

where we have defined the effective returns to mortgage borrowing and housing for young households as

$$
R_{t+1, m}^{Y}=\frac{1}{q^{Y}\left(\hat{h}_{t}^{Y}, \hat{m}_{t}^{Y}\right)+\hat{m}_{t}^{Y} q_{m}^{Y}\left(\hat{\alpha}_{t}^{Y}\right)},
$$

and

$$
R_{t+1, h}^{Y}=G \frac{\left(1-\delta_{H}\right) P_{t+1}}{P_{t}-\rho_{t}^{Y}-\hat{m}_{t}^{Y} q_{h}^{Y}\left(\hat{\alpha}_{t}^{Y}\right)^{\prime}},
$$

and further the effective return to deposits

$$
R_{t+1, d}^{Y}=\frac{1+r_{t}}{1-\left(1+r_{t}\right) \hat{m}_{t}^{Y} q_{d}^{Y}\left(\hat{\alpha}_{t}^{Y}\right)^{\prime}},
$$

and to endowment shares for $k=Y, M$

$$
\begin{aligned}
R_{t+1, \eta}^{Y Y} & =\frac{v Y_{t+1}+p_{t+1}^{Y}}{p_{t}^{Y}-\hat{m}_{t}^{Y} q_{\eta}^{Y}\left(\hat{\alpha}_{t}^{Y}\right)^{\prime}} \\
R_{t+1, \eta}^{Y M} & =\frac{(1-v) Y_{t+1}+B_{t+1}^{O}}{p_{t}^{Y}-\hat{m}_{t}^{Y} q_{\eta}^{Y}\left(\hat{\alpha}_{t}^{Y}\right)} .
\end{aligned}
$$


Mortgage pricing function derivatives. To compute the effective returns on all assets, we need to calculate the derivative of the mortgage pricing function $q^{Y}\left(\hat{\alpha}_{t}^{Y}\right)$ with respect to the elements of $\hat{\alpha}_{t}^{Y}$. The first step is to differentiate the payoff function (9) with respect to these portfolio choices. We first define the home equity per dollar of mortgage debt of the marginal defaulter after bankruptcy losses

$$
\hat{\epsilon}_{t+1}^{Y Y}=\frac{(1-\xi)\left(1-\delta_{H}\right) P_{t+1} h_{t}^{Y} \bar{\epsilon}_{t+1}^{Y Y}}{m_{t}^{Y}}-1,
$$

and

$$
\hat{\epsilon}_{t+1}^{Y M}=\frac{(1-\xi)\left(1-\delta_{H}\right) P_{t+1} h_{t}^{Y} \bar{\epsilon}_{t+1}^{Y M}}{m_{t}^{Y}}-1 .
$$

Then we get

$$
\begin{aligned}
\frac{\partial \mathcal{P}_{t+1}^{Y}}{\partial m_{t}^{Y}} & =\frac{\hat{f}_{\epsilon, t+1}^{Y}}{\left(1-\delta_{H}\right) P_{t+1} h_{t}^{Y}}-\hat{F}_{\epsilon, t+1}^{Y}(1-\xi)\left(1-\delta_{H}\right) \frac{P_{t+1} h_{t}^{Y}}{\left(m_{t}^{Y}\right)^{2}} \\
\frac{\partial \mathcal{P}_{t+1}^{Y}}{\partial h_{t}^{Y}} & =\left(1-\delta_{H}\right) P_{t+1}\left[\hat{F}_{\epsilon, t+1}^{Y} \frac{1-\xi}{m_{t}^{Y}}-\frac{\hat{f_{\epsilon, t+1}}}{\left(1-\delta_{H}\right) P_{t+1} h_{t}^{Y}}\right] \\
\frac{\partial \mathcal{P}_{t+1}^{Y}}{\partial d_{t}^{Y}} & =-\hat{f}_{\epsilon, t+1}^{Y} \frac{\lambda^{Y}}{\left(1-\delta_{H}\right) P_{t+1} h_{t}^{Y}} \\
\frac{\partial \mathcal{P}_{t+1}^{M}}{\partial \eta_{t}^{M}} & =-\hat{\hat{f}}_{\epsilon, t+1}^{Y} \frac{\lambda^{Y}}{\left(1-\delta_{H}\right) P_{t+1} h_{t}^{Y}}
\end{aligned}
$$

where we use the auxiliary functions

$$
\begin{aligned}
& \hat{f}_{\epsilon, t+1}^{Y}=\pi^{Y} f_{\epsilon, t+1}^{M}\left(\bar{\epsilon}_{t+1}^{Y M}\right) \hat{\epsilon}_{t+1}^{Y M}+\left(1-\pi^{Y}\right) f_{\epsilon, t+1}^{Y}\left(\bar{\epsilon}_{t+1}^{Y Y}\right) \hat{\epsilon}_{t+1}^{Y Y}, \\
& \hat{F}_{\epsilon, t+1}^{Y}=\pi^{Y} \int_{0}^{\bar{\epsilon}_{t+1}^{Y M}} \epsilon F_{\epsilon, t+1}^{M}(\epsilon)+\left(1-\pi^{Y}\right) \int_{0}^{\bar{\epsilon}_{t+1}^{Y Y}} \epsilon F_{\epsilon, t+1}^{Y}(\epsilon), \\
& \hat{\hat{f}}_{\epsilon, t+1}^{Y}=\pi^{Y} f_{\epsilon, t+1}^{M}\left(\bar{\epsilon}_{t+1}^{Y M}\right) \hat{\epsilon}_{t+1}^{Y M}\left(\bar{\epsilon}_{t+1}^{Y M}\right)^{2}+\left(1-\pi^{Y}\right) f_{\epsilon, t+1}^{Y}\left(\bar{\epsilon}_{t+1}^{Y Y}\right) \hat{\epsilon}_{t+1}^{Y Y}\left(\bar{\epsilon}_{t+1}^{Y Y}\right)^{2}, \\
& \hat{\hat{\epsilon}}_{\epsilon, t+1}^{Y}=\pi^{Y} f_{\epsilon, t+1}^{M}\left(\bar{\epsilon}_{t+1}^{Y M}\right) \hat{\epsilon}_{t+1}^{Y M}\left((1-v) Y_{t+1}+B_{t+1}^{O}\right)+\left(1-\pi^{Y}\right) f_{\epsilon, t+1}^{Y}\left(\bar{\epsilon}_{t+1}^{Y Y}\right) \hat{\epsilon}_{t+1}^{Y Y}\left(v Y_{t+1}+p_{t+1}^{Y}\right) .
\end{aligned}
$$

For any argument $\ell$ of the mortgage pricing function $q^{Y}$ we have that

$$
\frac{\partial q^{Y}\left(\alpha_{t}^{Y}\right)}{\partial \ell}=\mu_{t}^{I} \frac{\partial \mathcal{P}^{Y}\left(\underline{z}_{t}\right)}{\partial \ell}+\mathrm{E}_{t}\left[M_{t+1}^{I} \frac{\partial \mathcal{P}_{t+1}^{Y}}{\partial \ell}\right]
$$

With the first order conditions above, this characterizes the portfolio choice problem. 